\title{
Patterns of Exploitation and Biological Status of Pollock (Pollachius virens L.) in the Scotian Shelf, Georges Bank, and Gulf of Maine Area
}

\author{
Ralph K. Mayo \\ National Marine Fisheries Service, Northeast Fisheries Center \\ Woods Hole Laboratory, Massachusetts 02543, USA \\ Jacqueline M. McGlade' \\ Department of Fisheries and Oceans, Marine Fish Division \\ Bedford Institute of Oceanography, Dartmouth, Nova Scotia, B2Y 4A2, Canada \\ and \\ Stephen H. Clark \\ National Marine Fisheries Service, Northeast Fisheries Center \\ Woods Hole Laboratory, Woods Hole, Massachusetts 02543, USA
}

\begin{abstract}
Commercial exploitation of pollock in NAFO Divisions 4VWX and Subareas 5 and 6 has increased considerably over the past two decades as abundance of traditional groundfish species has declined. Total pollock landings from this area increased from less than 30,000 (metric) tons per year during the late-1960s to over 60,000 tons since 1985; USA recreational catches have contributed between 1,000 and 2,000 tons to the annual totals. Since 1977, when both the USA and Canada extended uni-lateral jurisdiction over their fishery resources to 200 miles, domestic management programs for pollock have been either non-existent or ineffective in restricting total landings.
\end{abstract}

Assessment and management advice for pollock has traditionally been predicated on the assumption of a single unit stock within the region. Tagging studies and morphometric and meristic measurements, however, suggest a possible separation of Gulf of Maine pollock from those on Browns Bank and Emerald Basin on the Scotian Shelf. The distribution of pollock eggs and larvae also indicates the presence of several spawning sites on the Scotian Shelf in addition to previously documented locations in the western Gulf of Maine. Sexual maturation and growth rates for pollock are similar throughout the region. Growth rates of males and females do not differ significantly, although the median size at maturity is slightly larger for males. The majority of pollock of both sexes become sexually mature during their third year.

Recruitment has been consistent since the late-1960s with one or more relatively strong year-classes appearing throughout the region every 3-4 years. Pollock become fully recruited to the fishery between ages 6 and 7 , although partial recruitment declines again after age 7 . Estimates of total stock size (age 2+), derived from virtual population analysis (VPA), increased from 102 million fish in 1974 to 145 million in 1977, but declined to 97 million in 1980 . Following recruitment of the 1979 year-class at age 2 in 1981 , stock size increased to 168 million before declining to 113 million in 1988. Instantaneous fishing mortality $(F)$ has exceeded $F_{0.1}(0.29)$ but remained at or below $F_{\max }(0.57)$ throughout the 1970 s. Fishing mortality has been close to $F_{\max }$, however, in 4 of the 6 years since 1982 .

Analyses of research vessel survey data generally agree with results obtained from the VPA, indicating a recent decline in stock abundance and biomass, and an increase in instantaneous total mortality. Equilibrium calculations suggest that fishing at $F_{0.1}$ would provide a long-term yield of 53,600 tons from a stock biomass of 317,700 tons, while fishing at $F_{\max }$ would provide a yield of 58,100 tons from a stock biomass of 204,600 tons. Corresponding spawning stock biomass levels at $F_{0.1}$ and $F_{\max }$ are 260,400 and 149,800 tons respectively. Although long-term yields are approximately $8 \%$ greater at the $F_{\max }$ level, fishing at $F_{0.1}$ provides for a $55 \%$ increase in total stock and $74 \%$ increase in spawning stock biomass over those allowed under $F_{\max }$.

'Present address: Max Planck Institute, IA Marconi Strasse, Julich D-5170, Federal Republic of Germany. 


\section{Introduction}

The pollock (Pollachius virens L.) is an Atlantic amphiboreal species. It has a number of synonymies, but is regarded as a distinct species within the family Gadidae and is the only representative of the genus Pollachius in the Northwest Atlantic.

Pollock constitute a significant component of the groundfish biomass on the Scotian Shelf and in the Gulf of Maine. Nominal commercial catches have been variable and often minor since commercial interest in this species has generally been less than that for haddock (Melanogrammus aeglefinus) and cod (Gadus morhua). During 1960-87, catches from the Scotian Shelf southward (Div. 4VWX and Subareas 5 and 6) averaged 41,900 (metric) tons, approximately $13 \%$ of the combined total for cod and haddock from these areas. Only small amounts, averaging about 1,000 tons annually since the mid-1960s, have been taken from the Grand Banks and St. Pierre Bank (Subarea 3), the Gulf of St. Lawrence (Div. 4RST) and off Labrador and West Greenland (Subareas 1 and 2).

Seasonal trends in commercial catches by area, tagging data and observed distributions of ripe adults, eggs and larvae, suggest that pollock exhibit a considerable degree of movement across the Scotian Shelf and within the Gulf of Maine, and that there are major spawning areas in the western Gulf of Maine and on Emerald, Browns and LaHave Banks on the Scotian Shelf (McGlade et al., MS 1985). There is also increasing evidence of spawning in other areas off southwestern Nova Scotia and on the Northeast Peak of Georges Bank, but as the migratory routes and the degree of intermixing among these areas have not been elucidated, pollock from Div. 4VWX and Subareas 5 and 6 (hereafter referred to as the Scotian Shelf-Gulf of Maine stock) have been considered as a unit for stock assessment and management purposes.

In this paper, fishery trends for the Northwest Atlantic pollock resource is reviewed with particular reference to the Scotian Shelf-Gulf of Maine stock, and information is provided on population structure and biological parameter estimates required for assessing the status of the resource. We also provide a retrospective view of stock assessment results in light of revised abundance, mortality and partial recruitment estimates and their implications for maximizing long-term yield.

\section{Distribution and Stock Structure}

\section{Adults and juveniles}

Pollock occur between Labrador and North Carolina (Steele, 1963), with highest concentrations on the Scotian Shelf and in the Gulf of Maine. North of the
Scotian Shelf, abundance has been insufficient to sustain a consistent commercial fishery (Templeman, 1966). Pollock inhabit depths ranging from 70 to $280 \mathrm{~m}$ with associated bottom temperatures between $5^{\circ}$ and $8^{\circ} \mathrm{C}$ in the Gulf of Maine and along the northern edge of Georges Bank (Leim and Scott, 1966) and on the Scotian Shelf from 35 to $380 \mathrm{~m}$ with bottom temperatures varying from $7.2^{\circ}$ to $8.6^{\circ} \mathrm{C}$ (Scott, 1982).

Pollock distribution in this region has also been determined from observations made during bottom trawl surveys conducted by the Canadian Department of Fisheries and Oceans and the United States National Marine Fisheries Service (Mayo et al., 1989). From December through March pollock concentrate in relatively shallow $(<100 \mathrm{~m})$ areas of the western Gulf of Maine (Div. 5Y) from the Great South Channel to Jeffreys Ledge (Fig. 1). Adults disperse to deeper (100-200 $\mathrm{m}$ ) offshore regions of the Gulf of Maine during spring and summer; juvenile harbor pollock reside primarily in shallow coastal waters during their first summer, but move offshore during the following winter (Steele, 1963). On the Scotian Shelf, highest concentrations of adults have traditionally occurred between Browns and Emerald Banks and off western Nova Scotia south of the Bay of Fundy (Div. $4 \mathrm{~W}$ and $4 \mathrm{X}$ ). Since 1986, however, significant numbers of relatively large pollock have been observed in Subdiv. $4 \mathrm{Vs}$ north of the Gully. Juvenile pollock have also been collected during Canadian summer surveys in offshore areas on the Scotian Shelf, although concentrations observed inshore during April and May suggest that onshore migration is an important component of their movement. However, the degree of intermixing between juveniles and adults in offshore areas and the relationship of inshore groups to offshore spawning aggregates have still not been determined.

Tagging studies of juvenile pollock conducted between 1982 and 1985 in Nova Scotia coastal waters indicate widespread dispersal across the Scotian Shelf, and some movement as far south as the Northeast Peak of Georges Bank and across the Gulf of Maine (W. Stobo, pers. comm., Marine Fish Division, Department of Fisheries and Oceans, Dartmouth, Nova Scotia). Further analyses to account for differences in fishing effort by area of capture, and future tagging of pollock in the western Gulf of Maine will be necessary before the extent of reciprocal movement between the Gulf of Maine and Scotian Shelf can be fully assessed.

\section{Eggs and larvae}

Concentrations of pelagic larvae were noted by Steele (1963) in the southern Gulf of Maine and south of Cape Cod during January and February, while subsequent collections taken from March through May found pollock larvae distributed throughout the Gulf of Maine due to passive transport by counter-clockwise cur- 


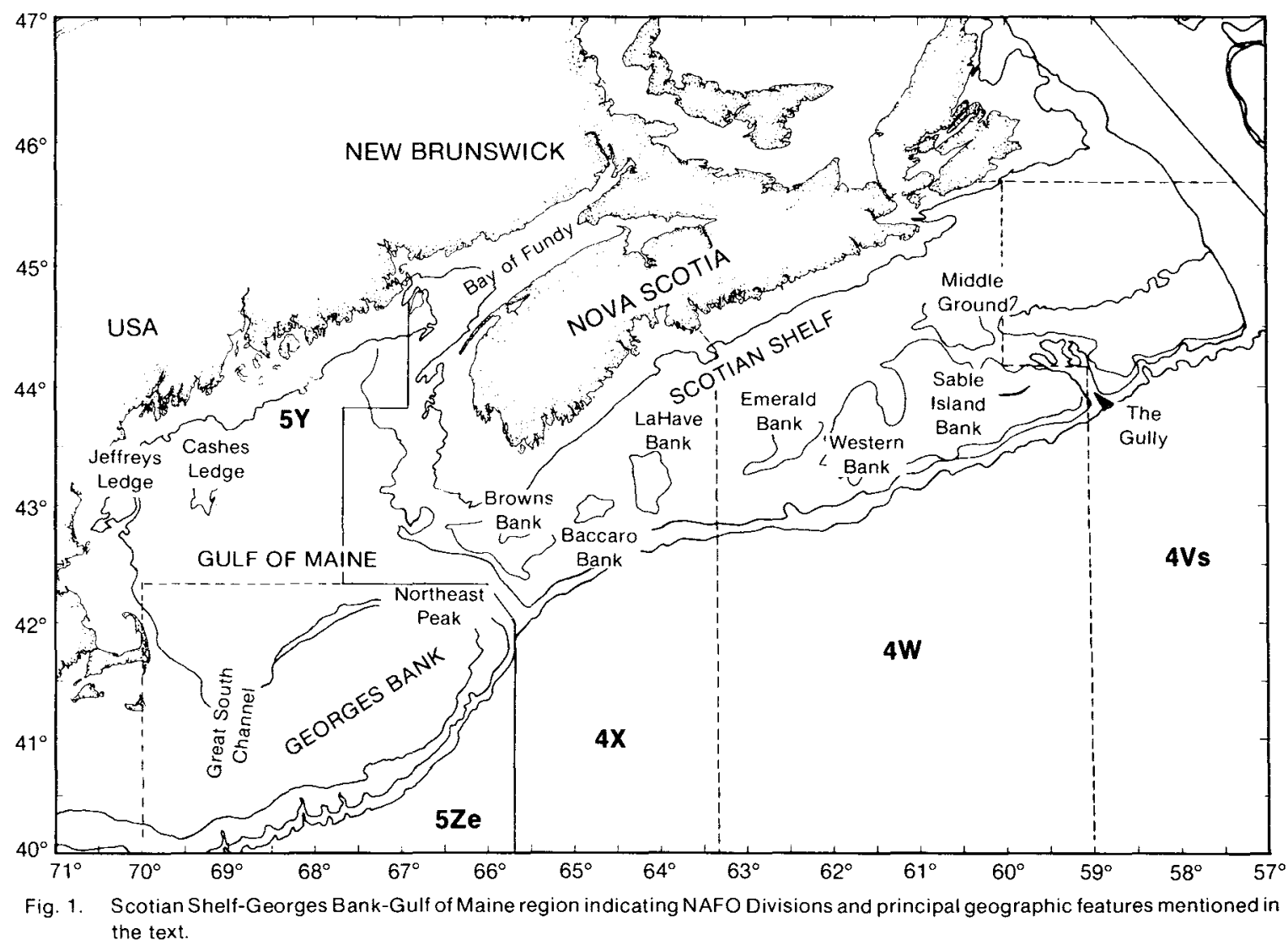

rents. Marak and Colton (1961) reported finding planktonic larvae in late March with no occurrence in subsequent samples taken in late May and early June, suggesting a pelagic residence time of 3-4 months.

More recent studies of the distribution of pollock eggs and larvae on the Scotian Shelf and in the Gulf of Maine have been based on data routinely collected through a number of sampling programs conducted by Canada and the USA (Fig. 2). Evaluations of these data have been published by Colton and Byron (1977), Colton et al. (1979), Scott (1980), Sherman (1980), Bolz et al. (1981), Sherman et al. (1981), O'Boyle et al. (1984), and Morse et al. (MS 1987). Composite distribution data provide a general indication of probable spawning areas within the region covered by each sampling program. The suggested spawning areas are: The Gully, Middle Ground, Western Bank, Emerald Bank and Emerald Basin, inshore along the southwestern coast of Nova Scotia, LaHave Bank, Baccaro and Browns Bank off Southwest Nova Scotia, the Northeast Peak of Georges Bank, on Jeffreys and Cashes Ledges, and in the Great South Channel in Subareas 5 and 6 . The Bay of Fundy does not appear to be a spawning areaperse, but rather an area of sporadic occurrence of ichthyoplankton coincident with large year-classes. There is no evidence at this time to support the likelihood of spawning in the upper part of the Gulf of Maine adjacent to the Bay of Fundy. Also, since we do not know the temporal dynamics of the dispersion of eggs and larvae, the relatively wide distribution on Georges Bank may be due to dispersal of larvae over the Bank rather than actual spawning activity.

\section{Stock definition}

Phenotypic characteristics derived from meristic and morphometric measurements and a modified truss configuration based on the outline of each fish (sensu Strauss and Bookstein 1982; McGlade and Boulding 1986), and genetic attributes based on electrophoretic analyses of tissue samples (McGlade et al., 1983) were examined to determine the degree of intermixing of adult pollock among known spawning grounds. Principal component and discriminant function analyses were performed as described by Ihssen et al. (1981), McGlade (MS 1983), and McGlade and Boulding (1986). Data were obtained during a series of Canadian and USA research cruises conducted during November and December between 1981 and 1985 in Emerald Basin, on Browns Bank and Jeffreys Ledge.

Multivariate analyses of meristic characteristics (McGlade et al., MS 1986) and morphometric measurements (McGlade and Boulding, 1986) showed clear differences among fish from the three areas. Electrophoretic analysis of 28 enzyme systems in pollock tissue from Emerald Basin and Jeffreys Ledge showed 


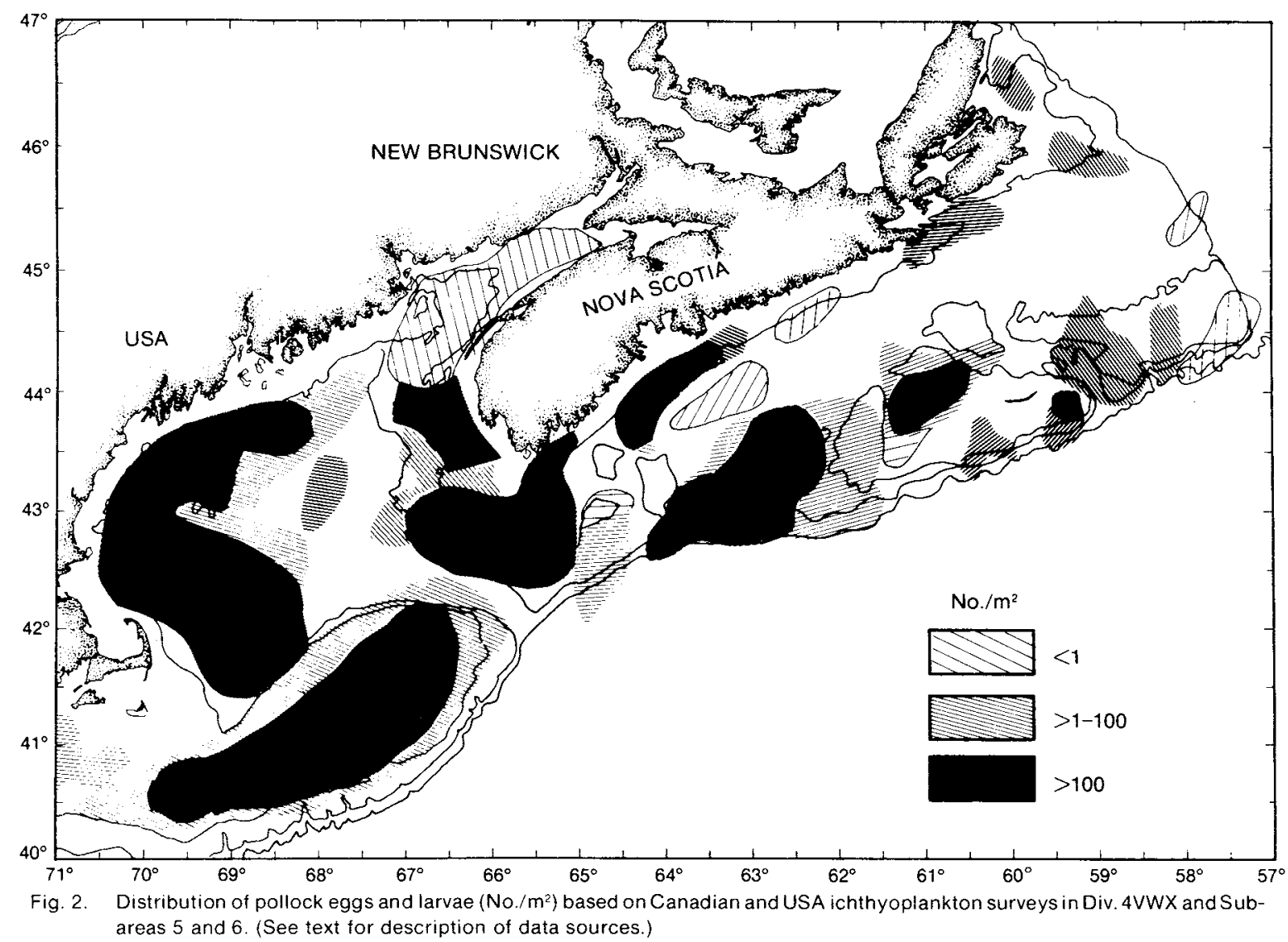

no significant differences $(P>0.05)$ between the two areas.

While these results do not provide a conclusive definition of pollock stock structure, the ichthyoplankton data suggest the presence of several spawning locations on the Scotian Shelf in addition to those previously identified in the western Gulf of Maine. Movement patterns of tagged juveniles from coastal Nova Scotia suggest a considerable amount of interchange among Div. $4 \mathrm{~V}, 4 \mathrm{~W}$, and $4 \mathrm{X}$ with some dispersal to Div. $5 Y$ and $5 Z$, but these results are preliminary and must be interpreted with caution due to the relatively low levels of fishing effort in the western Gulf of Maine compared to the Scotian Shelf. Given that meristic and morphometric differences were evident between pollock taken in Emerald Basin and those captured to the south and west, while genetic differences were not detected, these studies provide no additional evidence to refute the hypothesis of a unit stock throughout Div. $4 V W X$ and Subareas 5 and 6 . A more precise definition of management units will, therefore, require additional studies to better determine migratory patterns with particular reference to the degree of interchange between the Scotian Shelf and the Gulf of Maine-Georges Bank area.

\section{Assessment and Management History}

Specific management measures for pollock in the Northwest Atlantic were first introduced under the auspices of the International Commission for the Northwest Atlantic Fisheries (ICNAF) in 1973 as a preemptive total allowable catch (TAC) of 50,000 tons on pollock in Div. $4 X$ and Subarea 5 (ICNAF, 1973). The management area was extended to Div. $4 \mathrm{~V}$ and $4 \mathrm{~W}$ in 1974 and the TAC was adjusted upward to 55,000 tons and remained at that level through 1976 as stock assessments indicated no adverse effect from existing exploitation levels.

The first analytical stock assessment was completed in 1976 and the hypothesis of a unit stock in Div. $4 \mathrm{VWX}$ and Subarea 5 was examined and again accepted (ICNAF, 1976). Assessment results indicated that instantaneous fishing mortality $(F)$ had exceeded levels providing maximum yield-per-recruit $\left(F_{\max }\right)$ during 1973-75 and that abundance was declining (Clark et al., MS 1976; Halliday, MS 1976). Consequently, the 1977 TAC was reduced to 30,000 tons to prevent fishing mortality from exceeding $F_{\max }(0.40)$

With the implementation of extended fisheries jurisdiction in 1977, Canada and the USA assumed 
management responsibility for the pollock resource within their respective zones. The USA withdrew from ICNAF in December 1976, and since that time USA pollock catches have been unregulated. A draft Fishery Management Plan was prepared for the USA fishery in 1978 (NERFMC, MS 1978) but was not implemented. In 1987 , the USA implemented a management regime with an objective of maintaining target spawning stock biomass levels through minimum fish size and mesh and area restrictions.

Through the Canadian Atlantic Fisheries Scientific Advisory Committee (CAFSAC), Canada has based its management strategy on setting annual TACs to maintain fishing mortality at $F_{0.1}$ (Gulland and Boerema, 1973) to allow for rebuilding of the stocks to levels considered necessary to meet management objectives. Based on these objectives and annual evaluations by CAFSAC, Canada has maintained TACs in the 30,000-55,000 ton range since 1977 (Mayo et al., 1989).

From 1973 to 1976 nominal catches from Div. $4 \mathrm{VWX}$ and Subarea 5 remained below the TAC established by ICNAF, while the reduced TAC levels imposed between 1977 and 1980 were consistently exceeded. Since 1985, Canadian landings have remained relatively constant at about the TAC level, while the sharp increase in total catch reflects USA landings which were not included in recent Canadian allocations.

\section{Fishery Trends}

\section{Commercial landings}

Nominal catches from the Scotian Shelf-Gulf of Maine pollock stock have been strongly influenced by technological innovations, market demand and trends in fisheries directed towards other demersal species. Prior to the turn of the century, cod (taken mainly by 'long-lining') were of primary interest, and nominal catches of pollock by the USA averaged under 2,000 tons annually (Sette and Fiedler, MS 1929). Introduction of the otter trawl in 1905, coupled with more widespread use of bottom-set gill nets increased the annual average to about 8,000 tons during 1910-19 (Jensen, MS 1967). Total landings continued to increase during the next decade and, by the mid-1930s, exceeded 20,000 tons annually (Mayo et al., 1989). The upward trend continued through the 1940 s and 1950 s with total landings approaching 40,000 tons during the early1960 s in response to increased Canadian catches. Following a sharp decline during the late-1960s and early-1970s (ICNAF, 1960-78; NAFO, 1979-85; NAFO, 1987; NAFO, 1988), the total nominal commercial catch for this stock increased substantially to over 65,000 tons in 1986 and 1987 (Table 1, Fig. 3).

Historically, USA catches have been taken incidentally in offshore fisheries directed towards other demersal species (such as haddock and cod) and in

TABLE 1. Commercial landings of pollock (metric tons, live) from NAFO Divisions $4 \mathrm{WWX}$ and Subareas 5 and 6 by country, 1960-87.

\begin{tabular}{|c|c|c|c|c|c|c|c|c|c|c|}
\hline \multirow[b]{2}{*}{ Year } & \multicolumn{10}{|c|}{ Country } \\
\hline & Canada & FRG & GDR & Japan & Spain & USSR & UK & USA & Other & Total \\
\hline 1960 & 29,470 & - & - & - & 783 & - & - & 10,132 & 1 & 40,386 \\
\hline 1961 & 26,323 & - & - & - & 982 & - & - & 10,265 & 1 & 37,571 \\
\hline 1962 & 31,721 & - & - & - & - & - & - & 7,391 & - & 39,112 \\
\hline 1963 & 28,999 & 126 & - & - & - & 906 & 28 & 6,653 & - & 36,712 \\
\hline 1964 & 30,007 & 208 & - & - & - & 4,603 & 374 & 6,006 & 55 & 41,253 \\
\hline 1965 & 27,316 & 71 & - & - & 1,361 & 2,667 & 11 & 5,303 & - & 36,729 \\
\hline 1966 & 18,271 & - & - & - & 2,384 & 9,865 & 12 & 3,791 & - & 34,323 \\
\hline 1967 & 17,567 & - & - & - & 1,779 & 644 & 1 & 3,312 & 14 & 23,317 \\
\hline 1968 & 18,062 & - & - & - & 1,128 & 372 & - & 3,280 & 7 & 22,849 \\
\hline 1969 & 15,968 & 1,188 & 2,195 & - & 1,515 & 227 & - & 3,943 & 7 & 25,043 \\
\hline 1970 & 10,753 & 3,233 & 4,710 & 40 & 532 & 527 & - & 3,976 & - & 23,771 \\
\hline 1971 & 11,757 & 633 & 6,849 & 15 & 912 & 2,216 & - & 4,890 & 3 & 27,275 \\
\hline 1972 & 18,022 & 475 & 4,816 & 8 & 616 & 3,495 & 4 & 5,729 & 54 & 33,219 \\
\hline 1973 & 26,990 & 1,124 & 948 & 1.570 & 3.113 & 3,092 & - & 6,303 & 36 & 43,176 \\
\hline 1974 & 24,975 & 149 & 2 & 40 & 1,500 & 2,348 & 48 & 8,726 & 14 & 37,802 \\
\hline 1975 & 26,548 & 236 & 96 & - & 709 & 2,004 & - & 9,318 & 124 & 39,035 \\
\hline 1976 & 23,568 & 994 & 24 & - & 303 & 1,466 & - & 10,863 & 390 & 37,608 \\
\hline 1977 & 24,654 & 368 & - & 1 & 2 & 268 & - & 13,056 & 53 & 38,402 \\
\hline 1978 & 26,801 & - & - & 110 & - & 502 & - & 17,714 & 180 & 45,307 \\
\hline 1979 & 29,967 & 7 & - & 19 & - & 1,025 & - & 15,541 & 73 & 46,632 \\
\hline 1980 & 35,986 & - & - & 81 & - & 950 & - & 18,280 & 131 & 55,428 \\
\hline 1981 & 40,270 & - & - & 15 & - & 358 & - & 18,171 & 90 & 58,904 \\
\hline 1982 & 38,029 & - & - & 3 & - & 297 & - & 14,357 & 128 & 52,814 \\
\hline 1983 & 32,749 & - & - & 6 & - & 226 & - & 13,967 & 283 & 47,231 \\
\hline 1984 & 33,465 & - & 1 & 1 & - & 97 & - & 17,903 & 169 & 51,636 \\
\hline 1985 & 43,300 & - & - & 17 & - & 336 & - & 19,457 & 143 & 63,253 \\
\hline $1986^{a}$ & 42,975 & - & - & 51 & - & 564 & - & 24,549 & 391 & 68,530 \\
\hline $1987^{a}$ & 45,308 & - & - & 84 & - & 314 & - & 20,393 & 392 & 66,491 \\
\hline
\end{tabular}

a Provisional statistics 


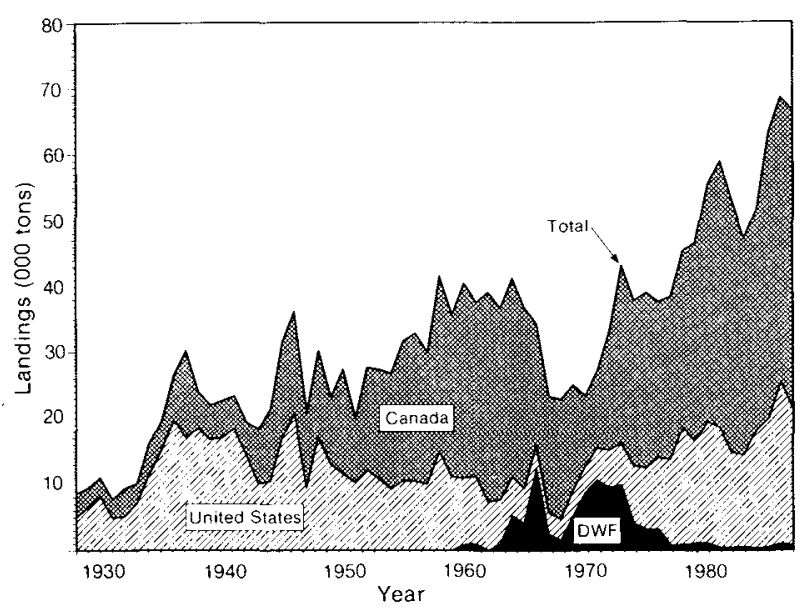

Fig. 3. Commercial landings (000 tons) of pollock by Canada, USA and distant water fleets (DWF) in Div. 4VWX and Subareas 5 and 6 during $1928-87$.

directed fisheries in coastal waters in the western Gulf of Maine (Ackerman, 1941). USA market demands were usually met rapidly and thus directed effort was generally not sustained when pollock moved out of coastal waters. The collapse of the Georges Bank haddock fishery during the late 1960 s (Clark et al., 1982) led to a federally subsidized program in the USA to redirect haddock effort to pollock but, due to low catches and prices, this program was only marginally successful (Grice, MS 1971). Declining USA and Canadian catches during the late 1960s and early 1970s are thought to reflect decreases in abundance and the decline in the Georges Bank haddock fishery; subsequent increases reflect improved recruitment and increased directed effort by both countries (Annand et al., MS 1987). A temporary post-1981 decline resulted largely from market conditions.

The Canadian fishery has evolved over the past decade from one in which pollock was taken as part of a mixed groundfish fishery to a directed fishery prosecuted primarily by tonnage class (TC) 4 and 5 side and stern trawlers operating in Div. 4VW and Subdiv. $5 \mathrm{Ze}$, and an inshore fishery conducted by smaller vessels (TC 2 and 3) using bottom trawls, gillnets, longlines and fixed gear in Div. $4 X, 5 Y$ and $5 Z$. The USA catch in Subdiv. $5 Z$ e has been taken primarily in summer and autumn by TC 4 trawlers in directed operations for cod, haddock and other demersal species in the Great South Channel area and along the Northern Edge and North east Peak of Georges Bank. Most of the Div. 5Y catch has been taken incidentally or in operations directed towards spawning migrants by TC 2 and 3 trawlers, and gillnetters in the Jeffreys Ledge region of the Gulf of Maine in autumn and winter. USA catches have been taken primarily by trawlers, although the portion of the USA catch taken by gillnetting increased from less than $10 \%$ during $1971-72$ to $40 \%$ of the total throughout most of the 1980s (Mayo et al., 1989).
Prior to 1960, nominal catches of pollock were usually reported to ICNAF in "mixed groundfish" categories. Thus, catches by distant water fleets (DWF) were not documented but were probably not large. In later years, DWF pollock catches occasionally exceeded 10,000 tons but were taken primarily as bycatch. The majority of this catch from southward of the Scotian Shelf has been taken by the Union of Soviet Socialist Republics (USSR), the German Democratic Republic (GDR), Spain and the Federal Republic of Germany (FRG) (Table 1).

Distant water fleets caught over 12,000 tons in 1966, and sustained catches in excess of 9,000 tons were taken annually between 1970 and 1973 (Table 1). Throughout this period, USSR pollock catches were taken primarily as by-catch by TC 6 and 7 stern trawlers fishing for silver hake and other groundfish such as haddock on the central and western Scotian Shelf (Div. $4 \mathrm{WX}$ ) and on Georges Bank in summer and autumn. Spanish catches were taken primarily by TC $3+$ pair trawlers fishing for cod in the same area. FRG and GDR catches were generally taken in late autumn and winter by TC 6 and 7 trawlers on Georges Bank and in the Gulf of Maine; some of this catch appears to have been taken incidentally during midwater trawling operations for herring, but most resulted from redirection of effort to pollock after national herring allocations imposed under ICNAF had been filled.

Since $1960,60 \%$ of the catch has been taken from the western Scotian Shelf and Gulf of Maine (Div. $4 X$ and $5 Y$ ). Approximately $90 \%$ of the Canadian catch has been taken from the Scotian Shelf while USA catches during the 1960s and early-1970s were taken primarily from Georges Bank and the Gulf of Maine; in recent years, however, most of the USA catch has come from the western Gulf of Maine (Mayo et al., 1989).

Small quantities of pollock have also been taken off West Greenland and Labrador, on the Grand Bank, and in the Gulf of St. Lawrence (Subareas 1, 2 and 3 and Div. 4RST). Since the mid-1960s, nominal catches from this region have averaged approximately 1,000 tons annually. The bulk of this catch has been taken by Canada and Spain on the southern and western Grand Bank (Div. 3NO and Subdiv. 3Ps) as by-catch in operations directed toward cod, haddock and other species. Declining Canadian pollock catches on the Grand Bank during the early to mid-1960s were associated with declining catches in the haddock fishery (Templeman, 1966).

\section{Commercial catch-at-age}

Estimates of the age composition of the commercial catch are available from 1970 through 1987. McGlade and Annand (MS 1986) described the assumptions and stratification schemes employed in 
TABLE 2. Total catch-at-age in numbers (000's) and weight (tons), and average weight-at-age of pollock in the commercial fishery in NAFO Divisions $4 \mathrm{VWX}$ and Subareas 5 and 6, 1974-87.

\begin{tabular}{|c|c|c|c|c|c|c|c|c|c|c|c|c|c|c|}
\hline \multirow[b]{2}{*}{ Age } & \multicolumn{14}{|c|}{ Year } \\
\hline & 1974 & 1975 & 1976 & 1977 & 1978 & 1979 & 1980 & 1981 & 1982 & 1983 & 1984 & 1985 & 1986 & 1987 \\
\hline \multicolumn{15}{|c|}{ Number $(000)$} \\
\hline 2 & 261 & 260 & 234 & 56 & 115 & 299 & 361 & 699 & 247 & 94 & 64 & 248 & 60 & 93 \\
\hline 3 & 7,332 & 1.436 & 2,190 & 1,751 & 1,548 & 4,087 & 704 & 2,754 & 4,824 & 2,732 & 1,197 & 2,403 & 1,291 & 1,443 \\
\hline 4 & 3,445 & 5,297 & 3,085 & 3,779 & 3,618 & 7,487 & 3,798 & 1,309 & 2,245 & 11,166 & 5,191 & 2,878 & 6,019 & 3,180 \\
\hline 5 & 3,034 & 2,566 & 5,314 & 2,443 & 3,682 & 4,478 & 6,802 & 3,896 & 847 & 1,863 & 9,793 & 5,798 & 4,453 & 7,713 \\
\hline 6 & 1,359 & 2,400 & 1,454 & 2,980 & 1,887 & 2,184 & 4,096 & 4,720 & 2,599 & 427 & 1,251 & 8,081 & 5,234 & 4,091 \\
\hline 7 & 404 & 1,041 & 1,342 & 1.049 & 2.084 & 765 & 1,605 & 2,761 & 2.631 & 870 & 206 & 1.398 & 4,510 & 3.039 \\
\hline 8 & 213 & 263 & 272 & 673 & 602 & 531 & 469 & 964 & 1,349 & 994 & 374 & 211 & 494 & 2,117 \\
\hline 9 & 96 & 80 & 41 & 206 & 411 & 160 & 334 & 308 & 564 & 546 & 330 & 238 & 139 & 271 \\
\hline 10 & 100 & 85 & 15 & 81 & 151 & 62 & 110 & 268 & 268 & 280 & 194 & 353 & 268 & 80 \\
\hline 11 & 81 & 56 & 21 & 45 & 103 & 39 & 45 & 63 & 180 & 133 & 60 & 134 & 266 & 145 \\
\hline $12^{+}$ & 45 & 49 & 57 & 274 & 229 & 112 & 78 & 148 & 220 & 262 & 136 & 176 & 251 & 262 \\
\hline Total & 16,370 & 13,533 & 14,025 & 13,337 & 14,430 & 20,204 & 18,402 & 17,890 & 15,974 & 19,367 & 18,796 & 21,918 & 22,985 & 22,434 \\
\hline \multicolumn{15}{|c|}{ Weight (tons) } \\
\hline 2 & 214 & 224 & 140 & 46 & 97 & 218 & 343 & 433 & 148 & 69 & 66 & 174 & 48 & 67 \\
\hline 3 & 10,265 & 1,838 & 2,694 & 1.979 & 1,904 & 4,864 & 979 & 4,048 & 5,451 & 3,169 & 1,760 & 2,499 & 1,536 & 1,631 \\
\hline 4 & 6.752 & 10,541 & 5,892 & 6.046 & 6,512 & 12,279 & 7,406 & 3,246 & 5,725 & 18,536 & 11,161 & 5,555 & 11,135 & 6,169 \\
\hline 5 & 9,132 & 7,878 & 14,720 & 6,376 & 9,868 & 12,180 & 18,910 & 11,493 & 2,965 & 5.719 & 25,756 & 16,002 & 11,489 & 19,822 \\
\hline 6 & 5,558 & 9,240 & 5,365 & 10,519 & 7,454 & 7,710 & 14,377 & 16,190 & 10,786 & 1,776 & 4,391 & 26,102 & 17,796 & 12,437 \\
\hline 7 & 2,044 & 5,299 & 6,187 & 4,783 & 9,628 & 3,557 & 6,757 & 12,093 & 11,866 & 4,246 & 1,059 & 5,229 & 17,318 & 11,791 \\
\hline 8 & 1,304 & 1,715 & 1,510 & 3,816 & 3,486 & 3,000 & 2,650 & 5,620 & 7,123 & 5,139 & 2,151 & 1,087 & 2,391 & 9,082 \\
\hline 9 & 639 & 601 & 287 & 1,403 & 2,708 & 1,080 & 2,164 & 2,076 & 3,536 & 3,281 & 1,977 & 1,514 & 870 & 1,409 \\
\hline 10 & 736 & 650 & 116 & 572 & 1.022 & 463 & 849 & 1,994 & 1,967 & 1,882 & 1,265 & 2,234 & 1,830 & 573 \\
\hline 11 & 690 & 474 & 179 & 396 & 781 & 319 & 354 & 485 & 1,402 & 1,025 & 451 & 890 & 1,782 & 1,069 \\
\hline $12+$ & 448 & 490 & 526 & 2,482 & 1,816 & 931 & 690 & 1,218 & 1,819 & 2,321 & 1,161 & 1.515 & 2,018 & 2,206 \\
\hline Total & 37,782 & 38,950 & 37,616 & 38,418 & 45,276 & 46,601 & 55,479 & 58,896 & 52,788 & 47,163 & 51,198 & 62,801 & 68,213 & 66,256 \\
\hline \multicolumn{15}{|c|}{ Average weight (kg) } \\
\hline 2 & 0.82 & 0.86 & 0.60 & 0.83 & 0.84 & 0.73 & 0.95 & 0.62 & 0.60 & 0.73 & 1.03 & 0.70 & 0.80 & 0.72 \\
\hline 3 & 1.40 & 1.28 & 1.23 & 1.13 & 1.23 & 1.19 & 1.39 & 1.47 & 1.13 & 1.16 & 1.47 & 1.04 & 1.19 & 1.13 \\
\hline 4 & 1.96 & 1.99 & 1.91 & 1.60 & 1.80 & 1.64 & 1.95 & 2.48 & 2.55 & 1.66 & 2.15 & 1.93 & 1.85 & 1.94 \\
\hline 5 & 3.01 & 3.07 & 2.77 & 2.61 & 2.68 & 2.72 & 2.78 & 2.95 & 3.50 & 3.07 & 2.63 & 2.76 & 2.58 & 2.57 \\
\hline 6 & 4.09 & 3.85 & 3.69 & 3.53 & 3.95 & 3.53 & 3.51 & 3.43 & 4.15 & 4.16 & 3.51 & 3.23 & 3.40 & 3.04 \\
\hline 7 & 5.06 & 5.09 & 4.61 & 4.56 & 4.62 & 4.65 & 4.21 & 4.38 & 4.51 & 4.88 & 5.14 & 3.74 & 3.84 & 3.8 \\
\hline 8 & 6.12 & 6.52 & 5.55 & 5.67 & 5.79 & 5.65 & 5.65 & 5.83 & 5.28 & 5.17 & 5.75 & 5.15 & 4.84 & 4.2 \\
\hline 9 & 6.66 & 7.51 & 7.00 & 6.81 & 6.59 & 6.75 & 6.48 & 6.74 & 6.27 & 6.01 & 5.99 & 6.36 & 6.26 & 5.2 \\
\hline 10 & 7.36 & 7.65 & 7.72 & 7.06 & 6.77 & 7.47 & 7.72 & 7.44 & 7.34 & 6.72 & 6.52 & 6.33 & 6.83 & 7.16 \\
\hline 11 & 8.52 & 8.47 & 8.54 & 8.79 & 7.58 & 8.18 & 7.87 & 7.70 & 7.79 & 7.71 & 7.52 & 6.64 & 6.70 & 7.37 \\
\hline $12+$ & 9.95 & 9.99 & 9.23 & 9.06 & 7.93 & 8.31 & 8.84 & 8.23 & 8.27 & 8.86 & 8.54 & 8.61 & 8.04 & 8.42 \\
\hline
\end{tabular}

the catch-at-age calculations, and Mayo et al. (1989) reviewed sampling levels and provided estimates of catch in number and weight and average weights-atage for Canada, USA and the DWF components. Prior to 1974 , sampling of the commercial catch was limited and catch-at-age estimates for several cohorts were highly variable. Therefore, only data from 1974 through 1987 were included in the present study. Catches and mean weight-at-age matrices combined over all fleets are given in Table 2.

The combined mean weights-at-age represent averages taken over the three fleet components weighted by numbers landed on an annual basis. Catch biomass estimates are computed as the product of numbers-at-age and mean weights-at-age. The total annual weight calculated over all ages in most years is within $1 \%$ of the tabulated landings given in Table 1.
Total catches by number have been dominated by age 3-7 fish throughout the series, although considerable inter-annual variability is evident as dominant yearclasses progress through the fishery. Several moderate to strong year-classes have supported the fishery over the past decade and the substantial increase in landings since 1985 has been supported by recruitment from the very strong 1979 year-class, augmented by further contributions from the 1980 and 1982 yearclasses. In 1987, the total catch was well distributed among several year-classes with ages ranging from 4 to 8. Landings by Canada and USA have generally been supported by the same dominant year-classes (Mayo et al., 1989).

Catch biomass is generally dominated by ages 4 through 8 , although strong year-classes have made significant contributions at age 3 in some years. Aver- 
age weights-at-age during 1974-87 do not exhibit any consistent trends over time (Table 2).

\section{Commercial CPUE}

Commercial catch-per-unit-effort (CPUE) indices (Table 3) were calculated for USA TC 3 and 4 side and stern trawlers, and Canadian TC 5 stern trawlers using 1970-87 landings and effort data from trips in which pollock comprised $50 \%$ or more of the total landed weight or was recorded as the main species for the trip. Indices for USA TC 3 and 4 vessels were computed on a seasonal and annual basis for trips which fished in Div. $5 Y$ and 5Z. CPUE calculations for Canadian vessels were based on trips which fished from June to August and from April to November by composite areas of Div. $4 \mathrm{VWX}$ and Subarea 5.

USA March-September indices suggest a gradual but steady increase in CPUE between 1970 and 1977 , followed by a slight decline through 1984 and a sharp decline from 1985 through 1987. The Canadian catchrate series reflect the same general trend, i.e. an approximate doubling of CPUE from the early-1970s through the early-1980s, followed by a sharp decline in 1983. The Canadian series, however, exhibit considerable inter-annual variability since the early-1980s, a possible result of trip limits and other regulatory measures imposed since 1983 (Annand et al., MS 1988).

Seasonal analyses suggest that CPUE indices associated with the directed winter fishery on spawning aggregations of pollock are less sensitive to fluc- tuations in abundance than corresponding indices during the summer months. Annual USA CPUE indices, and those which were based on autumn-winter months (October through February) fluctuated considerably with no evident trends. Indices which were based solely on spring-summer months (March through September), however, indicated a gradual but steady increase in relative abundance between 1970 and 1977 , followed by a slight decline through 1984 and a sharp decline between 1985 and 1987.

Commercial CPUE indices which were computed from USA data pooled over all months correspond to those developed from the autumn-winter data because most directed pollock trips occur during winter when the fish are found in spawning concentrations in the western Gulf of Maine. The remaining trips, conducted during spring and summer, occur when pollock are more dispersed throughout the area, and account for a relatively low proportion of the total directed effort.

From both the USA and Canadian results, it can be postulated that increased concentrations of pollock during the winter spawning season can generate transient increases in availability sufficient to produce consistently high annual CPUE indices independent of the overall level of stock abundance, particularly when the exploitation rate is relatively low. In this case, changes in seasonal availability are great enough to mask the effects of changes in stock abundance on CPUE. Conversely, CPUE indices which are based on trips fishing during the remainder of the year should provide a more accurate measure of relative stock abundance since

TABLE 3. USA and Canadian commercial catch-per-unit-effort (CPUE) indices for pollock based on otter trawl trips in which pollock comprised $50 \%$ or more of the total catch. (See text for description of spatial and temporal level of resolution employed in the computations.)

\begin{tabular}{|c|c|c|c|c|c|c|}
\hline \multirow[b]{3}{*}{ Year } & \multicolumn{4}{|c|}{$U_{S A}^{a}$} & \multirow{2}{*}{\multicolumn{2}{|c|}{$\frac{\text { Canada }}{\text { Tonnage class } 5}$}} \\
\hline & \multicolumn{2}{|c|}{ Tonnage class 3} & \multicolumn{2}{|c|}{ Tonnage class 4} & & \\
\hline & Mar-Sep & All months & Mar-Sep & All months & Jun-Aug & Apr-Nov \\
\hline 1970 & 3.02 & 3.56 & 4.44 & 7.64 & 0.74 & 0.86 \\
\hline 1971 & 2.88 & 4.13 & 5.03 & 7.80 & 0.78 & 0.64 \\
\hline 1972 & 3.58 & 8.70 & 6.79 & 5.88 & 0.81 & 0.75 \\
\hline 1973 & 4.35 & 7.52 & 6.50 & 6.65 & 1.07 & 0.75 \\
\hline 1974 & 5.04 & 7.25 & 6.05 & 8.82 & 0.58 & 0.66 \\
\hline 1975 & 4.43 & 5.47 & 8.17 & 7.45 & 0.61 & 0.70 \\
\hline 1976 & 4.42 & 5.63 & 7.39 & 9.57 & 0.52 & 0.57 \\
\hline 1977 & 7.19 & 7.89 & 8.89 & 9.14 & 0.69 & 0.78 \\
\hline 1978 & 5.95 & 6.77 & 9.11 & 9.58 & 0.84 & 0.89 \\
\hline 1979 & 5.23 & 6.18 & 7.04 & 6.16 & 1.16 & 1.09 \\
\hline 1980 & 6.28 & 7.28 & 6.82 & 7.88 & 0.97 & 0.94 \\
\hline 1981 & 4.58 & 7.30 & 6.02 & 8.03 & 0.89 & 1.01 \\
\hline 1982 & 5.29 & 5.64 & 6.37 & 6.75 & 1.58 & 1.32 \\
\hline 1983 & 6.06 & 5.86 & 7.00 & 8.26 & 0.87 & 1.05 \\
\hline 1984 & 5.61 & 6.17 & 6.34 & 5.77 & 1.28 & 1.33 \\
\hline 1985 & 4.13 & 5.32 & 3.79 & 4.17 & 0.70 & 0.96 \\
\hline 1986 & 4.54 & 5.26 & 3.40 & 3.36 & 1.38 & 1.26 \\
\hline 1987 & 2.34 & 3.12 & 3.10 & 3.28 & 0.84 & 0.94 \\
\hline
\end{tabular}

a USA CPUE calculated as tons per 24-hr day fished.

- Canadian CPUE calculated as tons per hour fished. 
availability effects are minor compared to variation in actual abundance.

\section{Recreational landings}

Recreational catch information for the USA has been collected in a series of national saltwater angling surveys conducted at approximate 5-year intervals between 1960-74 and, more recently, in a series of annual marine recreational fishery statistics surveys for the Atlantic and Gulf coasts initiated in 1979. A detailed description of the USA recreational fishery and an evaluation of survey methods is given by Mayo et al. (1989). Recreational catch data are not available for Canada, and it is assumed that Canadian recreational catches are of minor significance.

Recreational catch estimates declined from 4.3 million fish ( 9,800 tons) in 1960 to 2.5 million fish $(2,500$ tons) in 1970 (Table 4). The total recreational pollock catch, including those reportedly caught and released alive, averaged 4.1 million fish (1,600 tons) in 1979-80 but declined to 1.3 million in 1983 , although the estimated weight increased to 2,800 tons due to an increase in mean weight. In 1984, however, the total number and weight declined to 0.6 million fish and 276 tons respectively, as mean size also declined sharply. Except for a-slight increase in 1985, catches have remained relatively low since 1984 as have mean weights. Variation in mean weight is linked to recruitment of strong year-classes of juvenile pollock to the inshore regions of the Gulf of Maine (Mayo et al., 1989).

Since 1979 , over $90 \%$ of the total USA recreational catch-by-number was taken off Maine, New Hampshire and Massachusetts and over $70 \%$ was caught within 3 miles of the coast in bays and estuaries; approximately

TABLE 4. USA catches of pollock (numbers and total weight), and estimated mean weight derived from data collected in USA recreational fishery surveys, $1960-87$.

\begin{tabular}{lccc}
\hline Year & $\begin{array}{c}\text { Number } \\
(000)\end{array}$ & $\begin{array}{c}\text { Weight }^{\mathrm{b}} \\
\text { (tons) }\end{array}$ & $\begin{array}{c}\text { Mean } \\
\text { weight } \\
(\mathrm{kg})\end{array}$ \\
\hline 1960 & 4,335 & 9,834 & 2.27 \\
1965 & 3,756 & 4,240 & 1.13 \\
1970 & 2,451 & 2,533 & 1.03 \\
1974 & 481 & 496 & 1.03 \\
1979 & $3,648(2,349)$ & $1,021(658)$ & 0.28 \\
1980 & $4,446(1,997)$ & $2,134(959)$ & 0.48 \\
1981 & $2,724(1,602)$ & $1,226(721)$ & 0.45 \\
1982 & $1,686(882)$ & $2,563(1,341)$ & 1.52 \\
1983 & $1,314(590)$ & $2,799(1,257)$ & 2.13 \\
1984 & $642(405)$ & $276(174)$ & 0.43 \\
1985 & $2,147(1,860)$ & $862(747)$ & 0.40 \\
1986 & $447(359)$ & $219(176)$ & 0.49 \\
1987 & $741(278)$ & $296(111)$ & 0.40 \\
\hline
\end{tabular}

a Numbers in parentheses exclude data for pollock caught and released alive.

Deights calculated by multiplying numbers caught by mean weight of pollock available for identification in intercept (creel) survey work.
$80 \%$ of this catch was taken from small boats or from the shore or shore-based structures (U.S. Dept. Commerce, 1984, 1985a, 1985b, 1986, 1987). In Maine, about $70 \%$ of the total catch in number from 1960-85 consisted of juveniles. Juvenile pollock are available yearround in many inshore areas along the Maine coast and are taken in considerable numbers, while pollock also represent a substantial component of the offshore Maine catch (Nicholson and Ruais, MS 1979). In New Hampshire waters, pollock may account for over $40 \%$ of the total recreational catch-by-number during summer months. Length frequencies derived from sampling New Hampshire recreational pollock catches for 1979-82 (Fawcett, MS 1983) and intercept creel sampling of the catch during marine recreational fishery statistics surveys reveal a preponderance of age 0 and 1 fish (Witzig, Washington, D.C., pers. comm. 1985). It follows that, in recent years, juvenile pollock have been the major component of the recreational fishery. Since 1979 over $40 \%$ of the catch has been discarded live (Table 4), a higher percentage than that observed for most other species in these surveys.

Pollock are also common along the entire Massachusetts coast although they appear to be most available to recreational fishermen north of Cape Cod. In the Gulf of Maine they are taken primarily from June to November and may dominate offshore recreational catches for brief periods (Freeman and Walford, 1979a). They are taken in more limited numbers in the vicinity of Cape Cod, primarily in late spring; here, pollock usually move offshore by June and do not return until early autumn (Nicholson and Ruais, MS 1979).

South and west of Cape Cod, pollock may be taken in inshore waters from October to May and also appear in deeper waters year-round as far south as Cape May, New Jersey (Freeman and Walford, 1979b). Catches in this region tend to peak in late spring and decline sharply during summer due to seasonal shifts in distribution and directed effort. Pollock are taken here primarily by party boats in directed fishing for cod and other species, although sporadic inshore fisheries may develop for juvenile pollock during years of high abundance (Wilk et al., MS 1979).

\section{Biological Parameters}

Indices of relative abundance and biomass (stratified mean number-and-weight-per-tow (kg), respectively) for pollock were computed from catch and age composition data collected during bottom-trawl surveys conducted by the USA Northeast Fisheries Center (NEFC) and the Canadian Department of Fisheries and Oceans (DFO). Catch data obtained from NEFC surveys were also transformed to $\ln (x+1)$, and retrans- 
formed estimates in original units were calculated as suggested by Bliss (1967) according to the relation:

$$
E\left(\bar{y}_{s t}\right)=e^{\left(\bar{y}_{s t}+\frac{s}{2}^{2}\right)}-1
$$

where $E\left(\bar{y}_{s t}\right)$ represents the estimated (retransformed) stratified mean catch-per-tow and $y_{s t}$ and $S^{2}$ represent the stratified mean and the estimated population variance respectively, in logarithmic units. Annual biomass and abundance indices for pollock derived from bottom-trawl surveys are extremely variable (Mayo et al, 1989) and recent attempts to normalize the data and increase precision (Almeida et al., MS 1986) have been unsuccessful. For this reason, trawl-survey data were used primarily to identify dominant year-classes, evaluate recruitment and estimate growth, maturation and total-mortality rates. Results from Commonwealth of Massachusetts Division of Marine Fisheries (DMF) inshore surveys of the western Gulf of Maine have also been used to compute pre-recruit indices. Further details concerning sampling design, survey operations and data preparation procedures in these surveys are provided by Grosslein (1969, MS 1974), Howe et al. (MS 1979), Azarovitz (1981), and Halliday and Koeller (1981). A more complete description of synoptic survey coverage is given by Mayo et al. (1989).

\section{Trends in relative abundance and biomass}

Retransformed indices derived from USA spring and autumn surveys indicate a gradual increase in biomass through the mid-1970s, followed by a sharp decline (Fig. 4). Both indices show biomass increases in 1985 and subsequent declines in 1986 and 1987. Canadian summer indices suggest that biomass and abundance remained relatively stable between 1970 and 1984, except for a sharp increase in 1980. Although Canadian indices have fluctuated sharply since 1985, the overall trend suggests a recent increase in both abundance and biomass due to large catches from strata in Div. 4V and 4W (Annand et al., MS 1988).

\section{Recruitment}

Much of the variation in overall abundance indices may be explained by differences in year-class strength. Peak abundance levels evident in USA spring surveys in 1972, 1976 and 1982, and autumn surveys in 1972-73 and $1976-77$ resulted from recruitment of strong 1970 , 1971,1975 and 1979 year-classes to the offshore survey area (Table 5). The 1969, 1971 and 1975 year-classes have been relatively strong throughout the Canadian summer survey series (Table 6) and, more recently, the 1982 index reflected recruitment of the strong 1979 year-class at age 3. Peak values evident in 1985 and 1987, however, resulted from catches of several relatively strong year-classes produced from 1979 through 1982 (Table 6). Age 0 and 1 indices derived from inshore DMF surveys in the western Gulf of Maine also

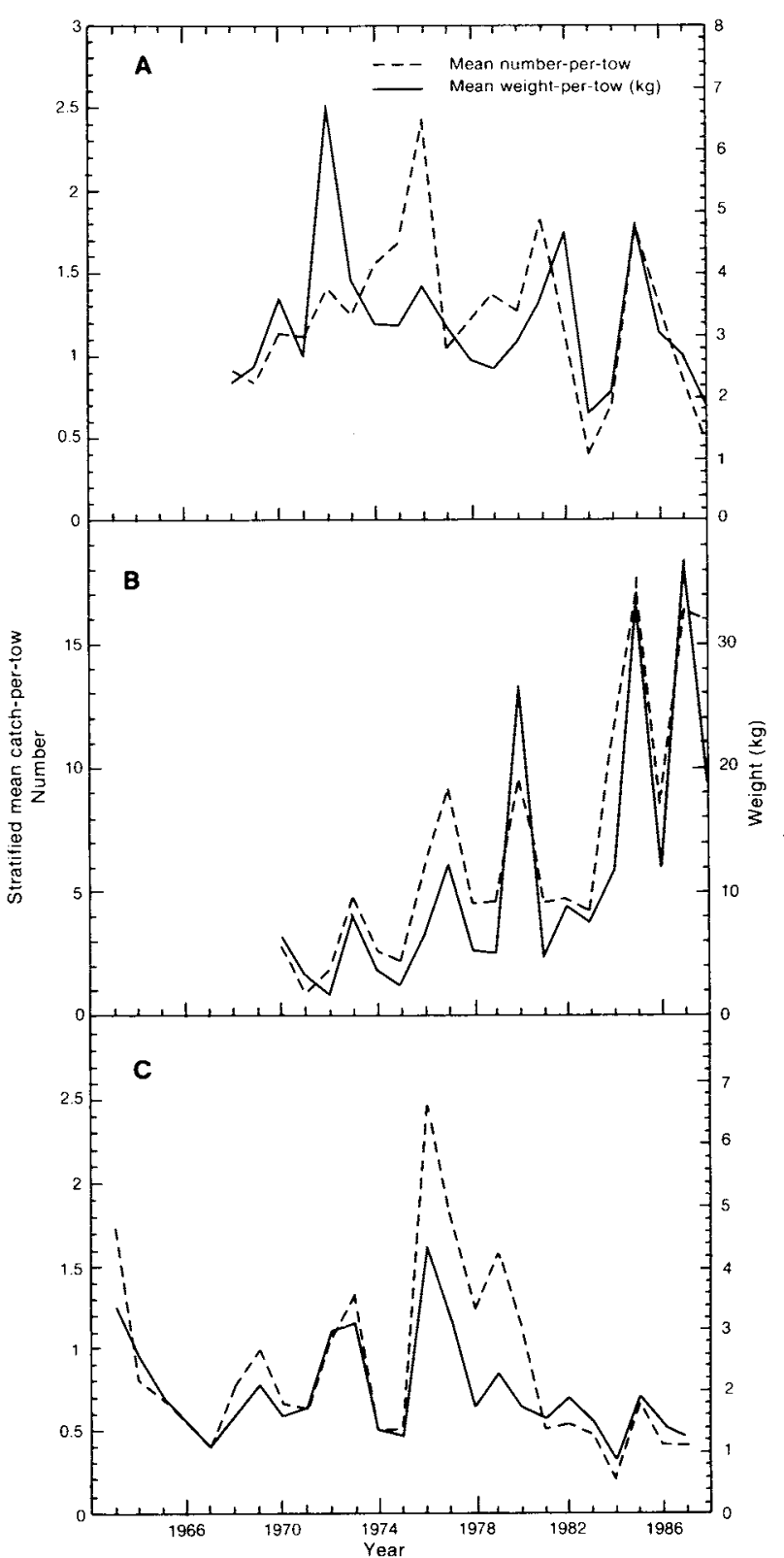

Fig. 4. Trends in stratified mean catch-per-tow derived from (A) USA spring, (B) Canadian summer, and (C) USA autumn, bottom trawl surveys conducted in Div. 4VWX and Subareas 5 and 6 during 1963-88.

revealed the strong 1979 and 1982 year-classes (Table 7).

Although the 1971 year-class has been the strongest and most persistent to appear in any survey, recent data have revealed relatively strong 1975, 1979 and 1982 year-classes. The recruitment of the 1971 yearclass increased overall stock biomass during the mid1970s and relatively high levels were sustained through the early-1980s by recruitment of subsequent strong year-classes. 
TABLE 5. Stratified mean catch-per-tow at age (numbers) for Scotian Shelf, Gulf of Maine, and Georges Bank pollock in NEFC offshore spring, summer, and autumn bottom trawl surveys, 1970-87.

\begin{tabular}{|c|c|c|c|c|c|c|c|c|c|c|c|c|c|c|c|c|c|}
\hline \multirow[b]{2}{*}{ Year } & \multicolumn{13}{|c|}{ Age } & \multicolumn{4}{|c|}{ Totals } \\
\hline & 0 & 1 & 2 & 3 & 4 & 5 & 6 & 7 & 8 & 9 & 10 & 11 & $12+$ & $1+$ & $4+$ & $5+$ & $6+$ \\
\hline \multicolumn{18}{|c|}{ Spring ${ }^{a, c}$} \\
\hline 1970 & 0.01 & 0.52 & 0.05 & 0.17 & 0.20 & 0.05 & 0.07 & 0.09 & 0.12 & 0.08 & 0.04 & 0.04 & 0.23 & 1.66 & 0.92 & 0.72 & 0.67 \\
\hline 1971 & 0.01 & 0.15 & 0.13 & 0.13 & 0.09 & 0.07 & 0.08 & 0.04 & 0.09 & 0.06 & 0.07 & 0.07 & 0.20 & 1.18 & 0.77 & 0.68 & 0.61 \\
\hline 1972 & - & 1.20 & 1.49 & 0.90 & 0.20 & 0.05 & 0.05 & 0.07 & 0.12 & 0.04 & 0.07 & 0.04 & 0.17 & 4.40 & 0.81 & 0.61 & 0.56 \\
\hline 1973 & - & 0.01 & 2.80 & 0.51 & 0.15 & 0.14 & 0.04 & 0.03 & 0.10 & 0.04 & 0.09 & 0.02 & 0.09 & 4.02 & 0.70 & 0.55 & 0.41 \\
\hline 1974 & - & 0.01 & 0.10 & 0.53 & 0.14 & 0.08 & 0.16 & 0.07 & 0.03 & 0.00 & 0.01 & 0.10 & 0.16 & 1.39 & 0.75 & 0.61 & 0.53 \\
\hline 1975 & - & 0.01 & 0.33 & 0.20 & 0.34 & 0.08 & 0.09 & 0.10 & 0.08 & 0.05 & 0.06 & 0.02 & 0.29 & 1.65 & 1.01 & 0.77 & 0.69 \\
\hline 1976 & - & 0.08 & 0.11 & 0.14 & 0.15 & 0.24 & 0.13 & 0.15 & 0.17 & 0.11 & 0.03 & 0.04 & 0.24 & 1.59 & 1.26 & 1.11 & 0.87 \\
\hline 1977 & - & 0.14 & 0.38 & 0.23 & 0.06 & 0.16 & 0.32 & 0.13 & 0.11 & 0.02 & 0.02 & 0.01 & 0.04 & 1.62 & 0.87 & 0.81 & 0.65 \\
\hline 1978 & - & 0.00 & 0.22 & 0.42 & 0.65 & 0.63 & 0.15 & 0.11 & 0.08 & 0.07 & 0.05 & 0.04 & 0.07 & 2.49 & 1.85 & 1.20 & 0.51 \\
\hline 1979 & - & 0.10 & 0.05 & 0.07 & 0.08 & 0.15 & 0.14 & 0.08 & 0.16 & 0.08 & 0.03 & 0.03 & 0.08 & 1.05 & 0.83 & 0.75 & 0.60 \\
\hline 1980 & - & 0.15 & 0.15 & 0.09 & 0.28 & 0.25 & 0.20 & 0.23 & 0.08 & 0.04 & 0.02 & 0.00 & 0.05 & 1.54 & 1.15 & 0.87 & 0.62 \\
\hline 1981 & - & 0.01 & 0.72 & 0.13 & 0.12 & 0.18 & 0.26 & 0.08 & 0.07 & 0.05 & 0.09 & 0.06 & 0.20 & 2.02 & 1.12 & 1.00 & 0.82 \\
\hline 1982 & - & 0.13 & 1.63 & 0.84 & 0.55 & 0.11 & 0.33 & 0.11 & 0.14 & 0.05 & 0.01 & 0.02 & 0.07 & 3.99 & 1.39 & 0.84 & 0.73 \\
\hline 1983 & - & 0.57 & 0.06 & 0.02 & 0.02 & 0.01 & 0.00 & 0.05 & 0.04 & 0.01 & 0.02 & 0.02 & 0.10 & 0.92 & 0.27 & 0.25 & 0.24 \\
\hline 1984 & - & 0.15 & 0.15 & 0.09 & 0.10 & 0.14 & 0.07 & 0.04 & 0.04 & 0.05 & 0.03 & 0.04 & 0.07 & 1.00 & 0.61 & 0.51 & 0.37 \\
\hline 1985 & - & 0.26 & 0.19 & 0.30 & 0.22 & 0.59 & 0.78 & 0.19 & 0.01 & 0.08 & 0.06 & 0.05 & 0.09 & 2.81 & 2.06 & 1.84 & 1.25 \\
\hline 1986 & - & 0.11 & 0.14 & 0.07 & 0.17 & 0.17 & 0.38 & 0.37 & 0.09 & 0.05 & 0.04 & 0.08 & 0.17 & 1.84 & 1.52 & 1.35 & 1.18 \\
\hline 1987 & - & 0.13 & 0.86 & 2.59 & 2.46 & 0.40 & 0.20 & 0.09 & 0.10 & 0.03 & 0.00 & 0.02 & 0.06 & 6.94 & 3.36 & 0.90 & 0.50 \\
\hline \multicolumn{18}{|c|}{ Summer ${ }^{b}$} \\
\hline 1977 & - & 0.05 & 0.23 & 0.09 & 0.26 & 0.29 & 0.32 & 0.15 & 0.23 & 0.07 & 0.08 & 0.07 & 0.23 & 2.07 & 1.70 & 1.44 & 1.15 \\
\hline 1978 & - & 0.00 & 0.57 & 0.17 & 0.09 & 0.08 & 0.08 & 0.05 & 0.09 & 0.03 & 0.01 & 0.05 & 0.08 & 1.30 & 0.56 & 0.47 & 0.35 \\
\hline 1979 & - & 0.05 & 0.00 & 0.38 & 0.26 & 0.36 & 0.55 & 0.36 & 0.49 & 0.06 & 0.21 & 0.00 & 0.23 & 2.95 & 2.52 & 2.26 & 1.90 \\
\hline 1980 & - & 10.67 & 0.11 & 0.06 & 0.29 & 0.25 & 0.30 & 0.22 & 0.03 & 0.02 & 0.07 & 0.05 & 0.13 & 12.20 & 1.36 & 1.07 & 0.82 \\
\hline \multicolumn{18}{|c|}{ Autumn ${ }^{a}$} \\
\hline 1970 & 0.01 & 0.13 & 0.08 & 0.01 & 0.09 & 0.08 & 0.08 & 0.04 & 0.02 & 0.01 & 0.02 & 0.01 & 0.07 & 0.64 & 0.42 & 0.33 & 0.25 \\
\hline 1971 & 0.02 & 0.11 & 0.38 & 0.16 & 0.02 & 0.06 & 0.09 & 0.04 & 0.08 & 0.03 & 0.01 & 0.01 & 0.09 & 1.08 & 0.43 & 0.41 & 0.35 \\
\hline 1972 & 0.00 & 0.38 & 0.27 & 0.20 & 0.08 & 0.07 & 0.08 & 0.07 & 0.05 & 0.04 & 0.03 & 0.03 & 0.10 & 1.40 & 0.55 & 0.47 & 0.40 \\
\hline 1973 & 0.00 & 0.03 & 0.71 & 0.12 & 0.17 & 0.11 & 0.11 & 0.09 & 0.07 & 0.00 & 0.12 & 0.02 & 0.10 & 1.65 & 0.79 & 0.62 & 0.51 \\
\hline 1974 & 0.00 & 0.00 & 0.08 & 0.28 & 0.20 & 0.11 & 0.08 & 0.09 & 0.01 & 0.02 & 0.00 & 0.02 & 0.02 & 0.91 & 0.55 & 0.35 & 0.24 \\
\hline 1975 & 0.01 & 0.22 & 0.06 & 0.03 & 0.11 & 0.07 & 0.04 & 0.09 & 0.01 & 0.01 & 0.01 & 0.01 & 0.03 & 0.68 & 0.37 & 0.26 & 0.19 \\
\hline 1976 & 0.00 & 0.03 & 0.03 & 0.15 & 0.55 & 1.63 & 0.50 & 0.31 & 0.14 & 0.05 & 0.01 & 0.01 & 0.29 & 3.70 & 3.49 & 2.94 & 0.31 \\
\hline 1977 & 0.00 & 0.06 & 0.17 & 0.24 & 0.29 & 0.42 & 0.38 & 0.22 & 0.11 & 0.09 & 0.02 & 0.00 & 0.14 & 2.14 & 1.67 & 1.38 & 0.96 \\
\hline 1978 & 0.00 & 0.03 & 0.19 & 0.04 & 0.04 & 0.09 & 0.09 & 0.15 & 0.08 & 0.06 & 0.04 & 0.03 & 0.12 & 0.96 & 0.70 & 0.66 & 0.57 \\
\hline 1979 & 0.00 & 0.01 & 0.02 & 0.26 & 0.33 & 0.19 & 0.13 & 0.08 & 0.09 & 0.05 & 0.04 & 0.01 & 0.06 & 1.27 & 0.98 & 0.65 & 0.46 \\
\hline 1980 & 0.01 & 0.13 & 0.01 & 0.01 & 0.05 & 0.11 & 0.06 & 0.07 & 0.13 & 0.08 & 0.06 & 0.04 & 0.07 & 0.82 & 0.67 & 0.62 & 0.51 \\
\hline 1981 & 0.00 & 0.07 & 3.59 & 0.98 & 0.14 & 0.20 & 0.13 & 0.04 & 0.00 & 0.00 & 0.01 & 0.00 & 0.08 & 5.24 & 0.60 & 0.46 & 0.26 \\
\hline 1982 & 0.01 & 0.07 & 0.44 & 0.40 & 0.29 & 0.01 & 0.05 & 0.04 & 0.02 & 0.02 & 0.00 & 0.02 & 0.04 & 1.40 & 0.49 & 0.20 & 0.19 \\
\hline 1983 & 0.00 & 0.49 & 0.03 & 0.05 & 0.04 & 0.07 & 0.01 & 0.06 & 0.08 & 0.03 & 0.02 & 0.02 & 0.06 & 0.98 & 0.41 & 0.37 & 0.30 \\
\hline 1984 & 0.00 & 0.12 & 0.18 & 0.02 & 0.01 & 0.01 & 0.03 & 0.00 & 0.00 & 0.02 & 0.02 & 0.02 & 0.02 & 0.45 & 0.13 & 0.12 & 0.11 \\
\hline 1985 & 0.00 & 0.62 & 0.05 & 0.08 & 0.07 & 0.12 & 0.07 & 0.01 & 0.00 & 0.00 & 0.03 & 0.01 & 0.04 & 1.10 & 0.35 & 0.28 & 0.16 \\
\hline 1986 & 0.00 & 0.21 & 0.22 & 0.14 & 0.13 & 0.07 & 0.04 & 0.04 & 0.00 & 0.00 & 0.00 & 0.01 & 0.02 & 0.88 & 0.31 & 0.18 & 0.11 \\
\hline 1987 & 0.00 & 0.05 & 0.21 & 0.06 & 0.00 & 0.05 & 0.02 & 0.08 & 0.06 & 0.04 & 0.00 & 0.01 & 0.02 & 0.60 & 0.28 & 0.28 & 0.23 \\
\hline
\end{tabular}

a Strata 13-40 (see Azarovitz, 1981).

- Strata 21-28 and 37-40 (see Azarovitz,1981).

"The "36 Yankee" trawl was used from 1970 to 1972 and 1982 to 1987; the "41 Yankee" trawl was used from 1973 to 1981 . No gear conversion factors are available to adjust for differences in fishing power.

\section{Mortality}

Estimates of instantaneous total mortality $(Z)$ were computed for individual year-classes from 1965-80 (Fig. 5) by constructing catch curves based on catchper-tow at age data derived separately from USA spring and autumn and Canadian summer bottom trawl surveys (Tables 5 and 6). A geometric mean of the three independent estimates was calculated as the best indicator of $Z$ for each year-class (Table 8 ). Average total mortality ranged from $0.30-0.42(G M=0.35)$ for the $1965-68$ year-classes to $0.35-1.32(\mathrm{GM}=0.63)$ for the 1977-80 year-classes. Results for the 1969-71 (GM = 0.53 ) and $1972-76$ year-classes ( $G M=0.42$ ) were intermediate. There were no evident trends in the year-class means among the three surveys except for a substantially lower mean for the 1977-80 year-classes in the Canadian summer surveys compared to the USA spring and autumn results. Thus, the increase in mean $Z$ associated with these year-classes is based entirely 
TABLE 6. Stratified mean catch-per-tow at age in numbers and weight ( $\mathrm{kg}$ ) for Scotian Shelf, Gult of Maine, and Georges Bank pollock in Canadian summer bottom trawl surveys, 1970-88. (From Annand $\theta t$ al., MS 1988)

\begin{tabular}{|c|c|c|c|c|c|c|c|c|c|c|c|c|c|c|c|c|c|}
\hline \multirow[b]{2}{*}{ Year } & \multicolumn{13}{|c|}{ Age } & \multicolumn{4}{|c|}{ Totals } \\
\hline & 1 & 2 & 3 & 4 & 5 & 6 & 7 & 8 & 9 & 10 & 11 & $12+$ & UK & $1+$ & $4+$ & $5+$ & $6+$ \\
\hline \multicolumn{18}{|c|}{ Mean number-per-tow } \\
\hline $1970^{\circ}$ & 0.007 & 1.815 & 0.445 & 0.270 & 0.197 & 0.178 & 0.120 & 0.066 & 0.025 & 0.000 & 0.035 & 0.007 & 0.000 & 3.165 & 0.898 & 0.628 & 0.431 \\
\hline 1971 & 0.000 & 0.733 & 0.607 & 0.168 & 0.039 & 0.018 & 0.027 & 0.011 & 0.007 & 0.018 & 0.000 & 0.000 & 0.000 & 1.628 & 0.288 & 0.120 & 0.081 \\
\hline 1972 & 0.000 & 0.019 & 0.013 & 0.146 & 0.321 & 0.140 & 0.037 & 0.068 & 0.049 & 0.024 & 0.012 & 0.026 & 0.004 & 0.859 & 0.827 & 0.681 & 0.360 \\
\hline 1973 & 0.000 & 0.389 & 0.477 & 2.146 & 0.812 & 0.086 & 0.052 & 0.049 & 0.060 & 0.002 & 0.018 & 0.011 & 0.014 & 4.116 & 3.250 & 1.104 & 0.292 \\
\hline 1974 & 0.007 & 0.039 & 0.798 & 0.199 & 0.259 & 0.121 & 0.129 & 0.073 & 0.055 & 0.036 & 0.074 & 0.031 & 0.000 & 1.821 & 0.977 & 0.778 & 0.519 \\
\hline 1975 & 0.000 & 0.009 & 0.018 & 0.324 & 0.279 & 0.374 & 0.059 & 0.092 & 0.036 & 0.008 & 0.009 & 0.000 & 0.000 & 1.208 & 1.181 & 0.857 & 0.578 \\
\hline 1976 & 0.000 & 0.029 & 0.219 & 0.667 & 1.239 & 0.310 & 0.534 & 0.197 & 0.043 & 0.044 & 0.015 & 0.048 & 0.011 & 3.356 & 3.108 & 2.441 & 1.202 \\
\hline 1977 & 0.000 & 0.261 & 0.770 & 0.985 & 2.029 & 1.415 & 0.184 & 0.308 & 0.108 & 0.052 & 0.030 & 0.012 & 0.004 & 6.158 & 5.127 & 4.142 & 2.113 \\
\hline 1978 & 0.000 & 0.007 & 0.147 & 0.607 & 0.944 & 0.351 & 0.328 & 0.102 & 0.048 & 0.022 & 0.000 & 0.023 & 0.017 & 2.596 & 2.442 & 1.835 & 0.891 \\
\hline 1979 & 0.000 & 0.000 & 0.108 & 0.621 & 0.780 & 0.566 & 0.232 & 0.167 & 0.010 & 0.036 & 0.000 & 0.000 & 0.023 & 2.543 & 2.435 & 1.814 & 1.034 \\
\hline 1980 & 0.012 & 1.142 & 1.250 & 3.305 & 5.195 & 1.314 & 0.715 & 0.206 & 0.077 & 0.041 & 0.000 & 0.000 & 0.029 & 13.286 & 10.882 & 7.577 & 2.382 \\
\hline 1981 & 0.007 & 0.159 & 0.175 & 0.051 & 0.506 & 0.505 & 0.352 & 0.243 & 0.109 & 0.076 & 0.028 & 0.013 & 0.046 & 2.270 & 1.929 & 1.878 & 1.372 \\
\hline $1982^{c}$ & 0.000 & 0.196 & 2.787 & 0.266 & 0.118 & 0.367 & 0.252 & 0.148 & 0.130 & 0.072 & 0.012 & 0.049 & 0.034 & 4.431 & 1.448 & 1.182 & 1.064 \\
\hline $1983^{\circ}$ & 0.100 & 0.119 & 0.916 & 1.702 & 0.196 & 0.048 & 0.090 & 0.262 & 0.166 & 0.056 & 0.059 & 0.020 & 0.027 & 3.761 & 2.626 & 0.924 & 0.728 \\
\hline 1984 & 0.035 & 0.469 & 0.228 & 0.699 & 2.007 & 0.306 & 0.210 & 0.456 & 0.689 & 0.427 & 0.071 & 0.156 & 0.044 & 5.797 & 5.065 & 4.366 & 2.359 \\
\hline 1985 & 0.007 & 1.481 & 4.557 & 3.511 & 3.371 & 2.689 & 0.399 & 0.111 & 0.201 & 0.312 & 0.109 & 0.101 & 0.003 & 16.852 & 10.807 & 7.296 & 3.925 \\
\hline 1986 & 0.044 & 0.606 & 0.653 & 0.959 & 1.002 & 1.370 & 0.999 & 0.070 & 0.011 & 0.101 & 0.135 & 0.086 & 0.007 & 6.043 & 4.740 & 3.781 & 2.779 \\
\hline 1987 & 0.000 & 0.590 & 2.442 & 3.673 & 5.817 & 2.283 & 1.656 & 1.348 & 0.052 & 0.114 & 0.088 & 0.345 & 0.028 & 18.436 & 15.404 & 11.731 & 5.914 \\
\hline 1988 & 0.020 & 0.029 & 0.557 & 1.090 & 2.142 & 1.908 & 1.794 & 0.993 & 0.576 & 0.040 & 0.042 & 0.159 & 0.000 & 9.350 & 8.744 & 7.654 & 5.512 \\
\hline \multicolumn{18}{|c|}{ Mean weight-per-tow (kg) } \\
\hline $1970^{\circ}$ & 0.001 & 1.054 & 0.520 & 0.683 & 0.691 & 0.853 & 0.747 & 0.475 & 0.207 & 0.000 & 0.330 & 0.059 & 0.000 & 5.620 & 4.045 & 3.362 & 2.671 \\
\hline 1971 & 0.000 & 0.343 & 0.558 & 0.368 & 0.122 & 0.075 & 0.134 & 0.066 & 0.048 & 0.104 & 0.000 & 0.000 & 0.000 & 1.818 & 0.917 & 0.549 & 0.427 \\
\hline 1972 & 0.000 & 0.012 & 0.011 & 0.330 & 1.143 & 0.720 & 0.215 & 0.426 & 0.347 & 0.160 & 0.097 & 0.210 & 0.005 & 3.676 & 3.653 & 3.323 & 2.180 \\
\hline 1973 & 0.000 & 0.181 & 0.604 & 4.805 & 2.364 & 0.376 & 0.278 & 0.303 & 0.385 & 0.022 & 0.158 & 0.144 & 0.085 & 9.705 & 8.920 & 4.115 & 1.751 \\
\hline 1974 & 0.001 & 0.020 & 0.828 & 0.307 & 0.794 & 0.547 & 0.701 & 0.444 & 0.389 & 0.281 & 0.648 & 0.314 & 0.000 & 5.274 & 4.425 & 4.118 & 3.324 \\
\hline 1975 & 0.000 & 0.003 & 0.021 & 0.587 & 0.870 & 1.449 & 0.320 & 0.615 & 0.287 & 0.075 & 0.094 & 0.000 & 0.000 & 4.321 & 4.297 & 3.710 & 2.840 \\
\hline 1976 & 0.000 & 0.016 & 0.335 & 1.560 & 3.848 & 1.238 & 2.710 & 1.111 & 0.303 & 0.385 & 0.121 & 0.434 & 0.109 & 12.170 & 11.819 & 10.259 & 6.411 \\
\hline 1977 & 0.000 & 0.178 & 0.916 & 2.092 & 5.892 & 5.062 & 0.882 & 1.765 & 0.762 & 0.407 & 0.238 & 0.099 & 0.033 & 18.326 & 17.232 & 15.140 & 9.248 \\
\hline 1978 & 0.000 & 0.006 & 0.141 & 1.337 & 2.847 & 1.544 & 1.613 & 0.681 & 0.356 & 0.138 & 0.000 & 0.225 & 0.160 & 9.048 & 8.901 & 7.564 & 4.717 \\
\hline 1979 & 0.000 & 0.000 & 0.136 & 1.332 & 2.413 & 2.339 & 1.219 & 1.121 & 0.072 & 0.288 & 0.000 & 0.000 & 0.235 & 9.155 & 9.019 & 7.687 & 5.274 \\
\hline 1980 & 0.000 & 0.873 & 1.568 & 6.232 & 1.693 & 3.939 & 2.655 & 1.294 & 0.530 & 0.284 & 0.000 & 0.000 & 0.275 & 19.343 & 16.902 & 10.670 & 8.977 \\
\hline 1981 & 0.001 & 0.105 & 0.312 & 0.123 & 1.577 & 1.950 & 1.604 & 1.314 & 0.753 & 0.637 & 0.218 & 0.088 & 0.496 & 9.178 & 8.760 & 8.637 & 7.060 \\
\hline $1982^{c}$ & 0.000 & 0.117 & 2.311 & 0.658 & 0.363 & 1.606 & 1.205 & 0.875 & 0.917 & 0.490 & 0.094 & 0.401 & 0.344 & 9.381 & 6.953 & 6.295 & 5.932 \\
\hline $1983^{d}$ & 0.013 & 0.053 & 1.157 & 2.658 & 0.631 & 0.185 & 0.404 & 1.241 & 0.879 & 0.382 & 0.433 & 0.163 & 0.246 & 8.445 & 7.222 & 4.564 & 3.933 \\
\hline 1984 & 0.012 & 0.261 & 0.353 & 1.746 & 6.193 & 1.398 & 1.094 & 2.620 & 4.271 & 2.901 & 0.545 & 1.324 & 0.472 & 23.190 & 22.564 & 20.818 & 14.625 \\
\hline 1985 & 0.001 & 0.613 & 4.571 & 6.103 & 8.517 & 8.826 & 1.503 & 0.535 & 1.187 & 1.715 & 0.777 & 0.776 & 0.027 & 35.151 & 29.966 & 23.863 & 15.346 \\
\hline 1986 & 0.009 & 0.288 & 0.764 & 1.804 & 2.806 & 5.156 & 4.126 & 0.339 & 0.065 & 0.646 & 0.819 & 0.574 & 0.065 & 17.461 & 16.400 & 14.596 & 11.790 \\
\hline 1987 & 0.000 & 0.198 & 1.797 & 5.569 & 2.415 & 6.661 & 6.282 & 5.478 & 0.301 & 0.729 & 0.494 & 2.587 & 0.242 & 32.753 & 30.758 & 25.189 & 22.774 \\
\hline 1988 & 0.004 & 0.017 & 0.536 & 2.062 & 6.205 & 6.556 & 7.072 & 4.616 & 2.854 & 0.272 & 0.305 & 1.281 & 0.000 & 31.780 & 31.223 & 29.161 & 22.956 \\
\hline
\end{tabular}

a Strata 40-95 (see Halliday and Koeller, 1981).

- 1970-81 data from R/N A. T. Cameron.

c 1982 data from R/V Lady Hammond.

- 1983-88 data from R/V Altred Needier.

TABLE 7. Stratified mean catch-per-tow in numbers and weight $(\mathrm{kg})$ for pollock from Massachusetts Division of Marine Fisheries inshore spring surveys, 1978-87

\begin{tabular}{ccccccc}
\hline Year & \multicolumn{1}{c}{ Stratified mean number per tow at age } & \multicolumn{2}{c}{$\begin{array}{c}\text { Stratified mean } \\
\text { weight }(\mathrm{kg}) \\
\text { per tow }\end{array}$} \\
\hline & 0 & 1 & 2 & $3+$ & Total $^{2}$ & 0.11 \\
1978 & 2.07 & 0.01 & 0.13 & 0.06 & 2.27 & 0.07 \\
1979 & 4.34 & 0.04 & 0.01 & 0.06 & 4.45 & 0.72 \\
1980 & 0.30 & 8.37 & 0.20 & 0.02 & 8.89 & 0.54 \\
1981 & 1.52 & 1.42 & 1.40 & 0.00 & 4.34 & 0.03 \\
1982 & 1.79 & 0.00 & 0.06 & 0.00 & 1.85 & 0.68 \\
1983 & 0.03 & 6.45 & 0.27 & 0.04 & 6.79 & 0.01 \\
1984 & 0.04 & 0.00 & 0.02 & 0.00 & 0.06 & 0.04 \\
1985 & 0.88 & 0.02 & 0.03 & 0.00 & 0.93 & $<0.01$ \\
1986 & 0.22 & 0.01 & 0.00 & 0.00 & 0.23 & 0.02 \\
1987 & 0.23 & 0.01 & 0.03 & 0.00 & 0.27 & \\
\hline
\end{tabular}

a Regions 1-5 (strata 11-21 and 25-26). See Howe et al., MS 1979.

on the USA survey results. Although estimates of $Z$ for later year-classes were based on younger fish, they suggest a lower rate of survival in the region covered by the USA surveys as indicated by trends in overall stock abundance presented above.

\section{Growth}

Although average longevity of pollock is approximately 20 years, signs of ageing as seen by the physiological-biochemical state of the fish, have been observed in specimens from age 11 (Storozhuk, 1978). Lengths up to $150 \mathrm{~cm}$ and weights of over $21 \mathrm{~kg}$ have been noted (Bigelow and Schroeder, 1953), and growth rates have been reported in several previous studies. Mavor (1918) observed winter rings on pollock scales and provided back-calculations of annual growth from samples collected in the Bay of Fundy, and Hoberman and Jensen (1962) computed back-calculated lengths at age from scale samples collected primarily from the southern Gulf of Maine. Steele (1963) established the 
validity of sectioned otoliths by noting the seasonal progression of opaque and hyaline edges and charac- terized growth of pollock from the Bay of Fundy and Scotian Shelf as rapid during the early years of life, with
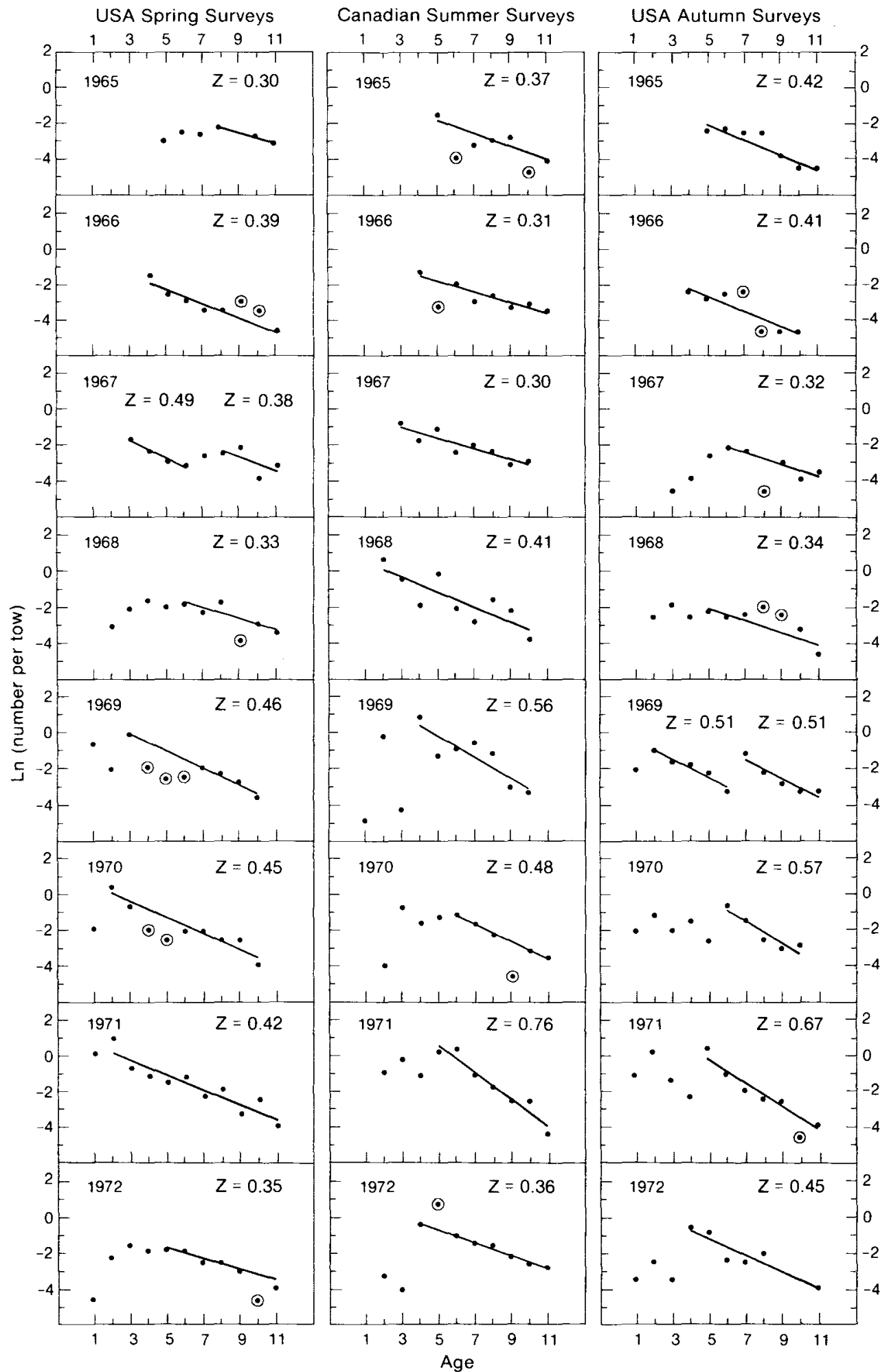

Fig. 5. Catch curves for the 1965-80 year-classes of pollock based on analyses of USA spring and autumn and Canadian summer bottom trawl survey data. (Circled points were excluded from the regressions.) 


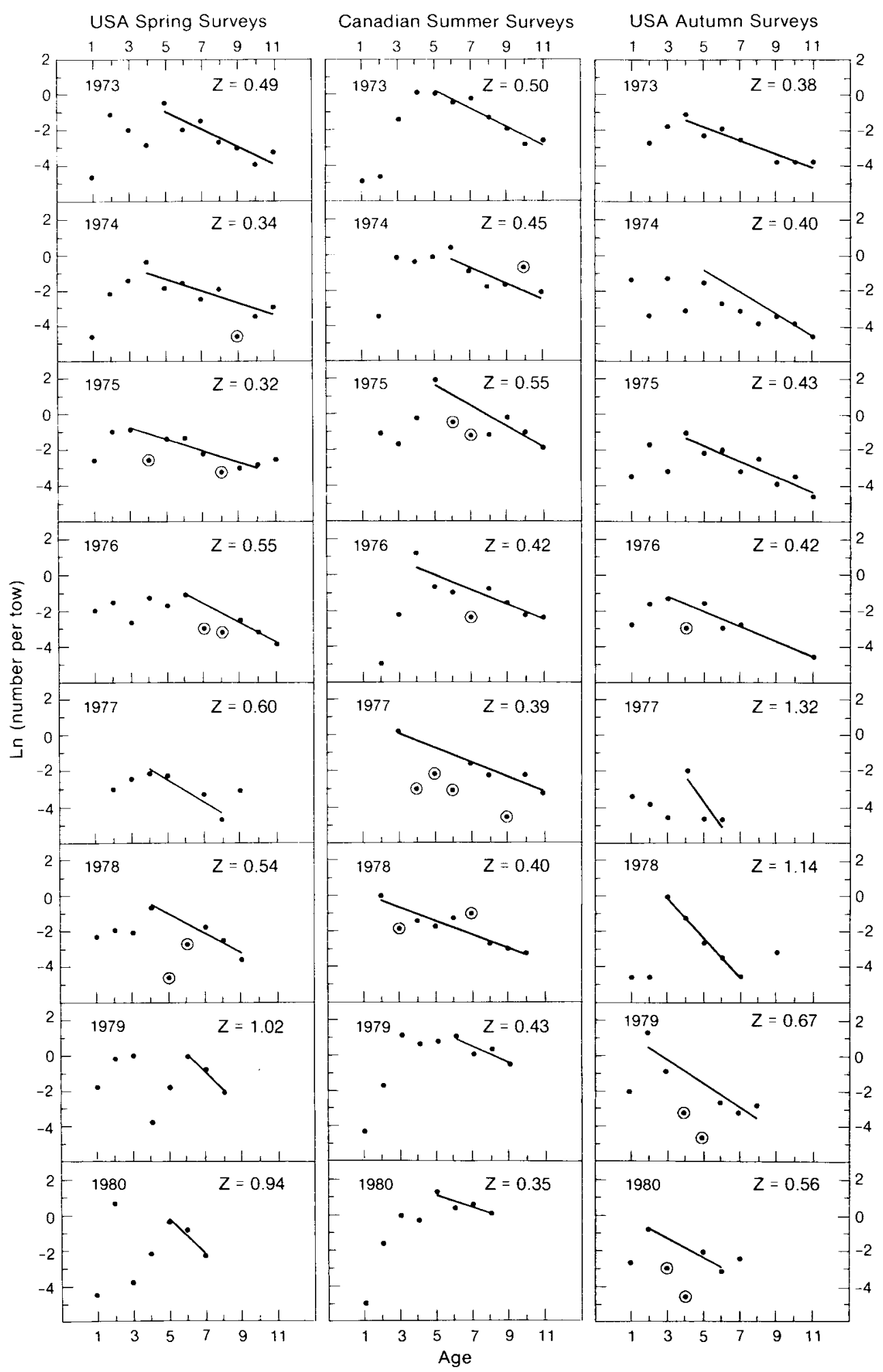

Fig. 5. (Cont'd).

a decline evident at the onset of sexual maturity at about age 6 . He also observed no appreciable differences in growth between males and females. Clark et al.
(1977, MS 1978) presented von Bertalanffy growth parameters based on ages from otoliths collected on USA and Canadian research vessel cruises conducted 
from 1970-76 in the Gulf of Maine and the Scotian Shelf. Their analyses suggested a slightly higher asymptotic length and lower growth coefficient for Scotian Shelf pollock compared to those taken from the Gulf of Maine.

In the present study, the original age data of Clark et al., (MS 1978) were re-examined in conjunction with more recent samples collected through 1984. Ages of 12,796 pollock have been determined from otoliths obtained during spring and autumn bottom trawl survey cruises conducted by the USA and summer cruises

TABLE 8. Estimates of total instantaneous mortality $(Z)$ derived from stratified mean catch-per-tow at age indices for pollock from USA spring and autumn, and Canadian summer bottom trawl surveys in the Scotian Shelf, Georges Bank and Gulf of Maine region.

\begin{tabular}{|c|c|c|c|c|}
\hline $\begin{array}{l}\text { Year- } \\
\text { class }\end{array}$ & $\begin{array}{l}\text { USA } \\
\text { spring }\end{array}$ & $\begin{array}{l}\text { Canada } \\
\text { summer }\end{array}$ & $\begin{array}{c}\text { USA } \\
\text { autumn }\end{array}$ & $\begin{array}{c}\text { Geometric } \\
\text { mean }\end{array}$ \\
\hline 1965 & 0.30 & 0.37 & 0.42 & 0.36 \\
\hline 1966 & 0.39 & 0.31 & 0.41 & 0.37 \\
\hline 1967 & 0.38 & 0.30 & 0.32 & 0.33 \\
\hline 1968 & 0.33 & 0.41 & 0.34 & 0.36 \\
\hline 1969 & 0.46 & 0.56 & 0.51 & 0.51 \\
\hline 1970 & 0.45 & 0.48 & 0.57 & 0.50 \\
\hline 1971 & 0.42 & 0.76 & 0.67 & 0.60 \\
\hline 1972 & 0.35 & 0.36 & 0.45 & 0.38 \\
\hline 1973 & 0.49 & 0.50 & 0.38 & 0.45 \\
\hline 1974 & 0.34 & 0.45 & 0.40 & 0.39 \\
\hline 1975 & 0.32 & 0.55 & 0.43 & 0.42 \\
\hline 1976 & 0.55 & 0.42 & 0.42 & 0.46 \\
\hline 1977 & 0.60 & 0.39 & 1.32 & 0.68 \\
\hline 1978 & 0.54 & 0.40 & 1.14 & 0.63 \\
\hline 1979 & 1.02 & 0.43 & 0.67 & 0.66 \\
\hline 1980 & 0.94 & 0.35 & 0.56 & 0.57 \\
\hline \multicolumn{5}{|c|}{$\begin{array}{c}\text { Geometric means } \\
\text { by year-classes }\end{array}$} \\
\hline $1965-80$ & 0.46 & 0.43 & 0.52 & 0.47 \\
\hline $1965-68$ & 0.35 & 0.34 & 0.37 & 0.35 \\
\hline $1969-71$ & 0.44 & 0.59 & 0.58 & 0.53 \\
\hline $1972-76$ & 0.40 & 0.45 & 0.42 & 0.42 \\
\hline $1977-80$ & 0.75 & 0.39 & 0.87 & 0.63 \\
\hline
\end{tabular}

conducted by Canada between 1970 and 1984 . To adjust the data to account for seasonal sampling differences, 0.3 year was added to ages obtained from spring cruises, 0.6 year to those from summer cruises, and 0.8 year, to those obtained on autumn cruises since nominal ages were originally assigned assuming a conventional 1 January birth date. Parameters of the von Bertalanffy growth equation $\left(\mathrm{L}_{\infty}, \mathrm{K}\right.$ and $\left.\mathrm{t}_{0}\right)$ were initially computed by season and year from the USA collection of 6,791 individual age-length observations to compare results over the 1970-84 period. A subset of the age data obtained from 1982 through 1984 was also analyzed to test for differential growth by sex. The 5,825 Canadian age-length observations, pooled during
1970-84, were analyzed both separately and in conjunction with the USA data set. Growth parameters were estimated by least squares fitting techniques for unequal age intervals as described by Tomlinson and Abramson (1961).

Results derived from the USA data set indicated no consistent differences in estimated growth parameters between spring and autumn cruises. However, estimates of $\mathrm{L}_{\infty}$ were lower in each analysis performed on the 1970-74 data as compared to those obtained using the 1975-84 data. In both analyses, ages ranged from 1 to 18 years. Results from the analyses of all USA and Canadian age data are provided in Table 9.

The USA results for the 1970-74 period are similar to those presented by Clark et al. (MS 1978) based on USA data collected between 1970 and 1976. These estimates, however, differ from Canadian results reported for the same period by Clark et al. (MS 1978), and from the Canadian and 1975-84 USA results given above. We believe that USA age determinations for the 1975-84 period are more representative than those obtained during the earlier years when USA ageing procedures for pollock were in the development stage. Results obtained from the 1975-84 USA data set and from the entire 1970-84 Canadian data set are consistent with previous Canadian estimates, indicating close agreement in ageing techniques. Therefore, a composite growth curve was determined by pooling the 1975-84 USA data subset with the entire 1970-84 Canadian data set. Resulting growth curves for USA, Canadian and composite data are presented in Fig. 6A. Further analyses (Table 9, Fig. 6 B) revealed no differential growth between sexes which is consistent with previous observations by Steele (1963).

\section{Maturation}

Considerable spatial and temporal variability in median size- and age-at-maturity has been reported for pollock on the Scotian Shelf (Beacham, 1983; McGlade et al., MS 1985) with median age generally lower for males (Steele, 1963; Beachman, 1983). In the present analysis, the existing series of maturity observations are extended so as to essentially encompass the southern limit of pollock distribution. Maturity stages of 5,362 pollock were determined by whole organ inspection during Canadian summer and USA spring and autumn research cruises from 1970 to 1984 and 1977 to 1984 respectively. Individual observations were pooled over all cruises to determine overall maturity-at-length relationships by sex, and to compare results obtained by each country. The number of mature pollock and total number observed were tabulated and summarized by sex and in $1 \mathrm{~cm}$ length intervals. A logistic curve was fitted by least squares to the summarized data for 3,296 females from Canadian cruises, and 1,109 females and 
TABLE 9. Estimates of von Bertalanffy growth parameters for pollock ( \pm 2 standard deviations) based on samples collected on USA and Canadian spring, summer, and autumn bottom trawl surveys between 1970 and 1984. (A) Sexes combined, (B) Separate analysis of male and female from USA data, 1982-84.

\begin{tabular}{lrrrr}
\hline Data set & \multicolumn{1}{c}{$\mathrm{L}_{\infty}$} & \multicolumn{1}{c}{$\mathrm{K}$} & \multicolumn{1}{c}{$\mathrm{t}_{0}$} & $\mathrm{~N}$ \\
\hline A. USA $(1970-74)$ & $97.6 \pm 1.1 \mathrm{~cm}$ & $0.2166 \pm 0.0074$ & $-0.0585 \pm 0.0513$ & 2,289 \\
USA $(1975-84)$ & $105.4 \pm 1.0 \mathrm{~cm}$ & $0.1781 \pm 0.0046$ & $-0.3734 \pm 0.0462$ & 4.682 \\
Can $(1970-84)$ & $107.3 \pm 1.9 \mathrm{~cm}$ & $0.1665 \pm 0.0068$ & $-0.1900 \pm 0.0575$ & 5,825 \\
USA $1975-84$ \\
Can 1970-84
\end{tabular}

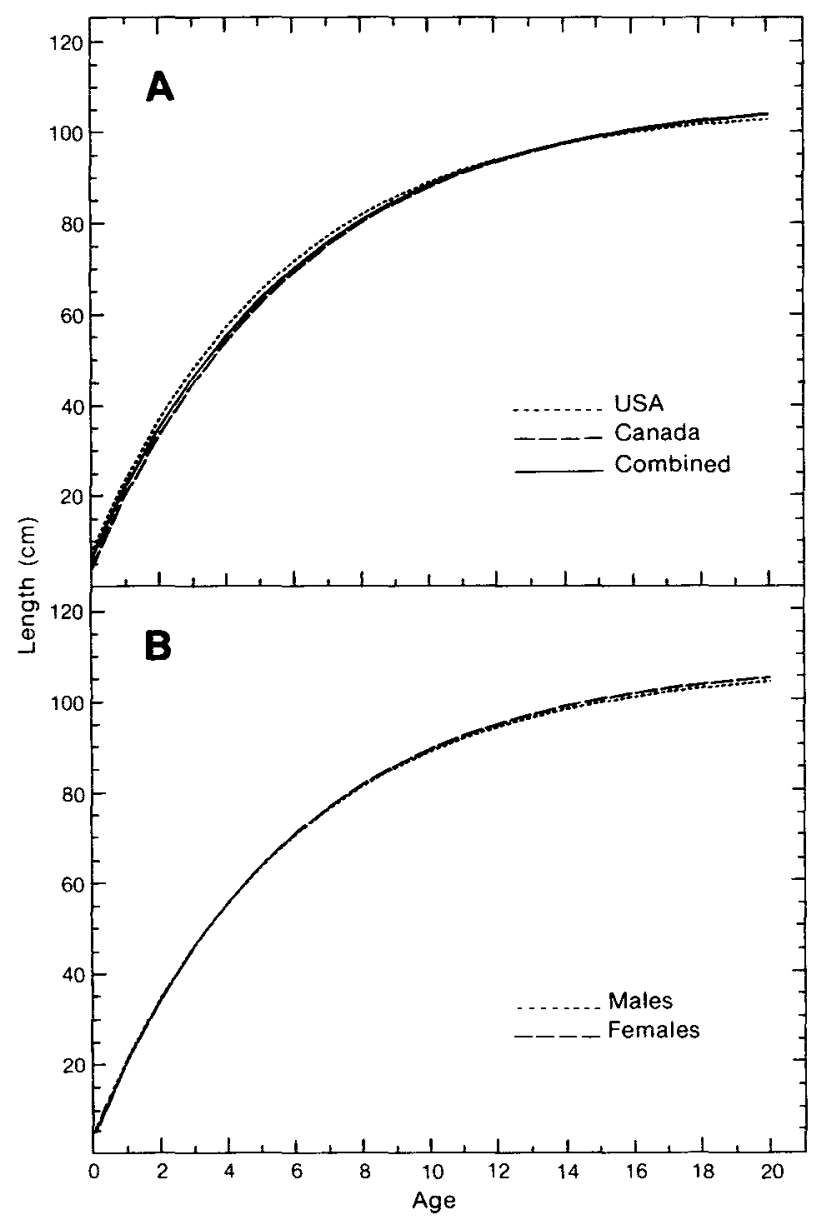

Fig. 6. Von Bertalantfy growth curves for: (A) pollock based on sample length-at-age data collected on USA and Canadian bottom trawl surveys during 1970-84 (sexes combined); and (B) for male and female pollock based on sample length-atage data collected on USA bottom trawl surveys during 198284.

957 males from USA cruises using BMDP statistical software for stepwise logistic regression (PLR) (Dixon, 1981). An approximation of the proportion mature-atage was estimated from the fitted curve by converting length to age using the composite von Bertalanffy growth equation described above.
Based on USA data, median lengths-at-maturity $\left(L_{50}\right)$ are estimated at 50.5 and $47.9 \mathrm{~cm}$ for males and females respectively, and $L_{50}$ for females estimated from Canadian samples is $47.4 \mathrm{~cm}$. The calculated $L_{50}$ for combined sexes is $49.5 \mathrm{~cm}$ (Fig. $7 \mathrm{a}$ ). Median agesat-maturity $\left(A_{50}\right)$ are estimated at 3.5 and 3.2 years for males and females respectively, and the calculated $A_{50}$ for combined sexes is 3.4 years (Fig. $7 \mathrm{~b}$ ). Plots of USA and Canadian maturity $v s$ length data and resulting logistic curves for females (Fig. 7c) illustrate several important differences. At any given length, USA data are more variable than the Canadian data, a probable result of the smaller USA sample size. The lower slope of the fitted USA ogive provides slightly lower estimates of rates of maturity in the $55-80 \mathrm{~cm}$ length range, although the $L_{50}$ values are similar.

Canadian observations were further analyzed to determine the extent of temporal changes in the maturity-at-age relationship. Analyses of female age and maturity data suggest that the median age-atmaturity has decreased from between 4 and 5 years in the early-1970s (1965-71 year-classes) to between 3 and 4 years by the late-1970s (1972-77 year-classes).

In contrast to previous studies by Steele (1963) and Beacham (1983), our analyses suggest that males attain sexual maturity at a slightly larger median size and later age than females. The similarity in $L_{50}$ estimates for females obtained from USA and Canadian samples indicate consistency in staging criteria. Determination of maturity by external examination of gonads is less accurate for smaller pollock as noted by Steele (1963) who stated that, at the time of sampling, it was difficult to distinguish small immature pollock from individuals which were recovering from spawning. Recent experiments which tested the classification of individuals by whole organ inspection versus histological examination also suggested that males are less often correctly staged than females. Thus, the relatively high $L_{50}$ estimate which were obtained for males may be a reflection of the incorrect classification of some small recovering males as immature. 

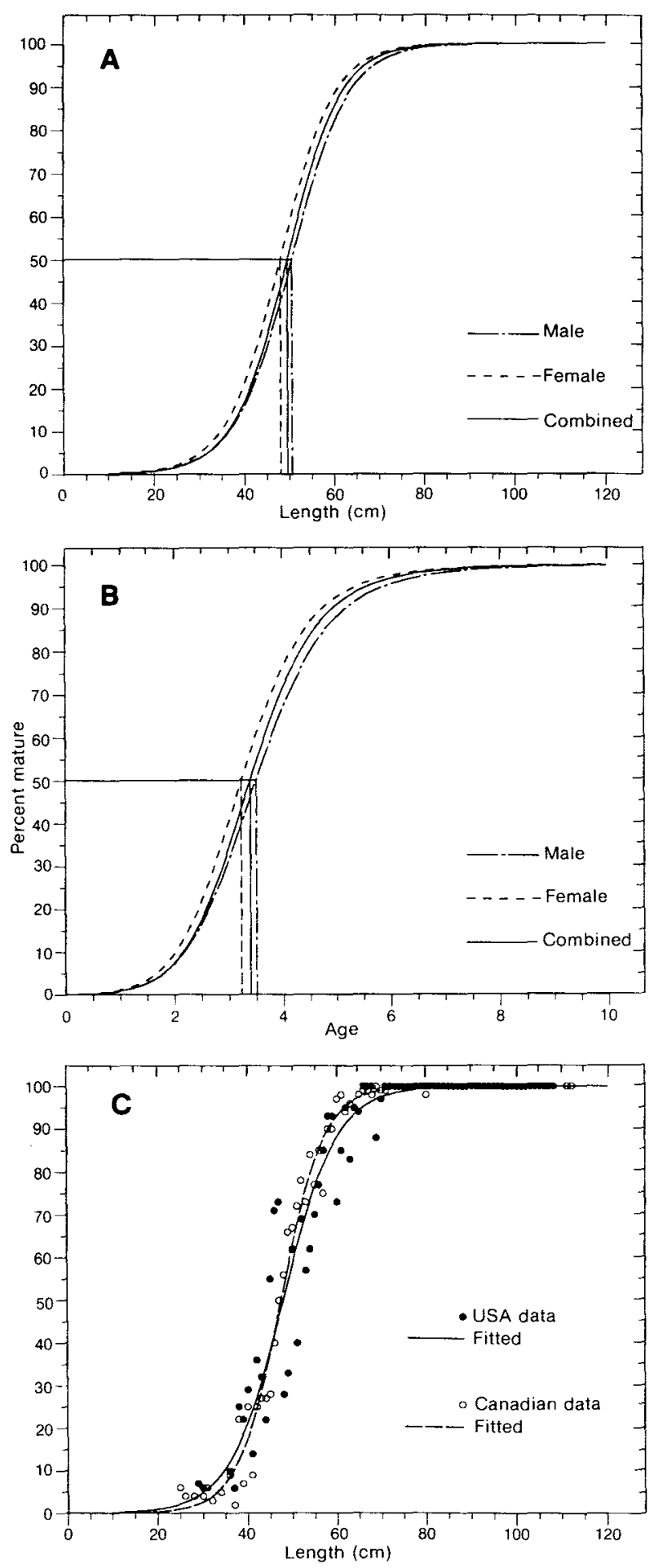

Fig. 7. Logistic curves of percent mature versus: (A) length by sex for pollock based on data collected on USA research vessel surveys in Div. 4VWX and Subareas 5 and 5 during 1977-84; (B) calculated age by sex for pollock based on data collected on USA research vessel surveys in Div. $4 \mathrm{VWX}$ and Subareas 5 and 6 during 1977-84; (C) length for female pollock based on data collected on USA and Canadian research vessel surveys in Div. 4VWX and Subareas 5 and 6 during 1970-84.
Although our estimates of $L_{50}$ and $A_{50}$ for both males and females are lower than those reported for the early-1960s by Steele (1963) for the Bay of Fundy and by Beacham (1983) for the Scotian Shelf, they are similar to Beacham's most recent results for Div. $4 X$ where a substantial decline in median size at maturity in the late 1970 s was noted.

\section{Stock Abundance and Biomass}

\section{Exploitation pattern}

Separable virtual population analysis (SVPA) (Pope and Shepherd, 1982) was employed to examine variability within the 1974-87 catch-at-age matrix from the commercial fishery (Table 2) and to define the longterm exploitation pattern(s). A reference age for unit selection of 5 years, an instantaneous natural mortality rate $(M)$ of 0.20 , and terminal $S\left(S_{1}\right)$ levels i.e. the $F$ on the oldest age relative to the reference age) ranging from 0.5 to 1.5 , were used in the analyses.

The exploitation pattern obtained in each analysis was distinctly dome-shaped with the most consistent patterns emerging when $S_{t}$ ranged from 0.5 to 1.0 . Results suggest that recruitment is essentially completed between ages 6 and 7 . The decrease in partial recruitment evident for the older ages may be directly related to recent increases in the use of gillnets, which exhibit dome-shaped selectivity patterns (Gulland and Harding, 1961), in the Canadian and USA pollock fisheries. Therefore, an $S_{t}$ of 0.75 at age 11 was used to obtain the following partial recruitment vector, adjusted to unity at age 7 , for use in equilibrium yield calculations:

\begin{tabular}{lllllllllll}
\hline Age (years) & 2 & 3 & 4 & 5 & 6 & 7 & 8 & 9 & 10 & 11 \\
\hline
\end{tabular}

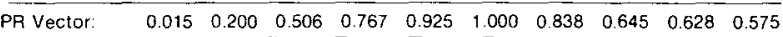

\section{Calibration of VPA}

The Hybrid method (Pope and Shepherd, 1985) was utilized to estimate terminal F-values corresponding to the oldest age of each cohort in 1987 using commercial catch and effort data. Disaggregated catch-at-age matrices for the Canadian, USA and DWF components from 1974-87 taken from Mayo et al. (1989) were included, although effort data were incorporated only for the Canadian and USA fleets. Fishing effort for the USA fleet was computed from CPUE indices obtained for $\mathrm{TC} 3+4$ side and stern trawlers fishing between March and September; effort for the Canadian fleet was based on TC 5 stern trawlers fishing between April and November (Table 3).

For each fleet, catchability coefficients (q) were predicted for each age in the terminal year (1987) from 
regressions of in q on year, with minimal weights given to the earliest years; estimates of terminal $F$ were obtained for each cohort from the product of fishing effort and $q$. The final terminal $F$ vector represents an average of the fleet-specific vectors, weighted by the inverse of the variance of $q$.

Age-specific stock size and fishing mortality estimates were derived from the final iteration of the calibration process using standard VPA calculations (Gulland, 1965) assuming an $M$ of 0.20 . Estimates of age $11 \mathrm{~F}$ for cohorts terminating between 1974 and 1986 were computed as an average $F$ of the 5 oldest ages in each year, and stock sizes for ages $12+$ in all years were derived by setting the plus group $F$ equal that for age 11. Stock biomass was computed by multiplying commercial mean weights-at-age (Table 2) by the age-specific stock-size estimates; spawning stock size was calculated by applying the maturity-at-age ogive described above for combined sexes to the agespecific stock sizes.

Average annual fishing mortality $\left(\overline{\boldsymbol{F}}_{\mathrm{c}}\right)$ and a weighted mean $F$ for ages 6 + were computed from the $F$ matrix for comparison with fishing effort. Estimates of $\bar{F}_{c}$ represent averages taken over the entire age spectrum weighted by catch-per-recruit, a measure which essentially reflects the combined effects of the exploitation rate $(F / Z)$ and cumulative $Z$ (Shepherd, 1983). Exploitable biomass $\left(B_{e}\right)$ estimates were computed for comparison with commercial CPUE indices as follows:

$$
B_{e}=\Sigma\left[\left(N_{i} / Z_{i}\right) *\left(1-e^{-Z_{i}}\right) * \bar{W}_{C_{i}} *\left(F_{i} / \bar{F}_{c}\right)\right]
$$

where

$$
\mathrm{N}_{\mathrm{i}}=\text { stock size at age } \mathrm{i} \text {, }
$$

$\bar{W} c_{i}=$ mean weight of a fish at age $i$ in the catch,

$F_{i}=$ instantaneous fishing mortality at age $i$, and

$Z_{i}=$ instantaneous total mortality at age $i$.

A multiple regression model with USA TC $3+4$ and Canadian TC 5 CPUE as independent variables, and $B_{e}$ as the dependent variable was chosen to assess the relationships between CPUE and exploitable biomass estimates. A similar model with USA and Canadian effort as independent variables and $\bar{F}_{c}$ as the dependent variable was used to examine $F$ versus effort relationships. Goodness-of-fit was evaluated by examining correlation coefficients and residual patterns between each pair of vectors. The CPUE model explained approximately $90 \%$ of the total variation in exploitable biomass; the Canadian index was highly significant $(P<0.001)$, and the USA index was significant $(P<0.05)$, but the intercept was not significant $(P>0.05)$. The fleet effort model explained less than $10 \%$ of the variation in $\bar{F}_{c}$ and was not significant. Attempts to model the more direct relationship between fleet fishing effort and $\bar{F}_{c}$ were not conclusive since regressions of $F$ on effort can be adversely affected by relatively low noise levels due to the intrinsically narrow dynamic range of the dependent variable (Pope and Shepherd, 1985).

Observed and predicted exploitable biomass estimates and corresponding Canadian and USA CPUE indices are illustrated in Fig. 8. Biomass and CPUE estimates increased throughout most of the 1970s, although USA and Canadian CPUE indices exhibited different rates of increase. Predicted values were slightly lower than levels observed since 1983. Although equal numbers of positive and negative residuals were obtained from the regression, a cluster of negative values associated with low biomass levels suggests a non-linear relationship between CPUE and biomass due to probable changes in q at different stock sizes (Gulland, 1964; Pope and Garrod, 1975).

\section{Fishing mortality}

Average fishing mortality remained relatively stable throughout most of the 1970s and early 1980s (Table 10) while recent increases in $F$ coincided with increased total commercial landings since 1985 (Table

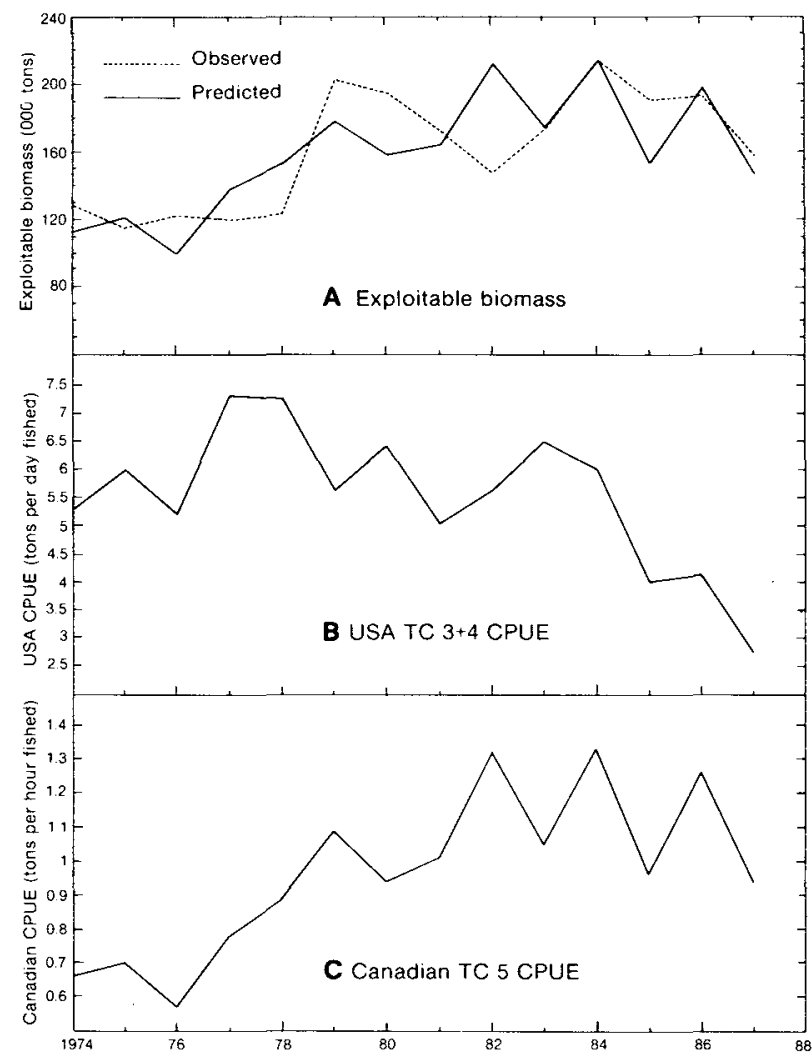

Fig. 8. Trends in (A) exploitable biomass and commercial catch-perunit-effort (CPUE) for (B) USA tonnage class $3+4$ and (C) Canadian tonnage class 5 trawlers in Div. 4 VWX and Subarea during 1974-87. 
TABLE 10. Estimates of 1974-87 instantaneous fishing mortality $(F)$ derived from virtual popuation analysis (VPA) of Div. $4 \mathrm{VWX}$ and Subareas 5 and 6 pollock catch-at-age.

\begin{tabular}{|c|c|c|c|c|c|c|c|c|c|c|c|c|c|c|}
\hline \multirow[b]{2}{*}{ Age } & \multicolumn{14}{|c|}{ Year } \\
\hline & 1974 & 1975 & 1976 & 1977 & 1978 & 1979 & 1980 & 1981 & 1982 & 1983 & 1984 & 1985 & 1986 & 1987 \\
\hline 2 & 0.011 & 0.008 & 0.006 & 0.001 & 0.004 & 0.037 & 0.017 & 0.008 & 0.005 & 0.003 & 0.001 & 0.013 & 0.004 & 0.003 \\
\hline 3 & 0.218 & 0.078 & 0.086 & 0.052 & 0.036 & 0.174 & 0.114 & 0.174 & 0.072 & 0.070 & 0.047 & 0.065 & 0.087 & 0.138 \\
\hline 4 & 0.295 & 0.242 & 0.238 & 0.209 & 0.145 & 0.245 & 0.243 & 0.319 & 0.209 & 0.235 & 0.183 & 0.154 & 0.230 & 0.320 \\
\hline 5 & 0.332 & 0.373 & 0.406 & 0.301 & 0.323 & 0.268 & 0.367 & 0.421 & 0.352 & 0.268 & 0.334 & 0.320 & 0.375 & 0.515 \\
\hline 6 & 0.397 & 0.477 & 0.376 & 0.420 & 0.402 & 0.323 & 0.420 & 0.470 & 0.554 & 0.301 & 0.291 & 0.508 & 0.535 & 0.710 \\
\hline 7 & 0.332 & 0.607 & 0.540 & 0.513 & 0.589 & 0.282 & 0.418 & 0.561 & 0.525 & 0.362 & 0.232 & 0.613 & 0.600 & 0.695 \\
\hline 8 & 0.473 & 0.376 & 0.311 & 0.578 & 0.633 & 0.289 & 0.280 & 0.478 & 0.595 & 0.385 & 0.261 & 0.395 & 0.456 & 0.636 \\
\hline 9 & 0.348 & 0.326 & 0.091 & 0.411 & 0.868 & 0.339 & 0.297 & 0.299 & 0.576 & 0.515 & 0.212 & 0.264 & 0.492 & 0.489 \\
\hline 10 & 0.441 & 0.593 & 0.093 & 0.262 & 0.605 & 0.297 & 0.414 & 0.413 & 0.462 & 0.638 & 0.346 & 0.367 & 0.533 & 0.591 \\
\hline 11 & 0.398 & 0.476 & 0.282 & 0.437 & 0.619 & 0.306 & 0.366 & 0.444 & 0.543 & 0.440 & 0.268 & 0.429 & 0.523 & 0.624 \\
\hline $12+$ & 0.398 & 0.476 & 0.282 & 0.437 & 0.619 & 0.306 & 0.366 & 0.444 & 0.543 & 0.440 & 0.268 & 0.429 & 0.523 & 0.624 \\
\hline \multicolumn{15}{|l|}{ Mean } \\
\hline $\bar{F}_{c}$ & 0.296 & 0.340 & 0.309 & 0.320 & 0.367 & 0.230 & 0.285 & 0.342 & 0.358 & 0.273 & 0.241 & 0.331 & 0.354 & 0.428 \\
\hline Age $6+$ & 0.390 & 0.496 & 0.404 & 0.451 & 0.527 & 0.309 & 0.398 & 0.485 & 0.548 & 0.399 & 0.270 & 0.501 & 0.555 & 0.678 \\
\hline
\end{tabular}

TABLE 11. Estimates of 1974-87 stock size (000 of fish) derived from virtual population analysis (VPA) of Div. $4 \mathrm{VWX}$ and Subareas 5 and 6 pollock catch-at-age, and projections for 1988

\begin{tabular}{|c|c|c|c|c|c|c|c|c|c|c|c|c|c|c|c|}
\hline \multirow[b]{2}{*}{ Age } & \multicolumn{15}{|c|}{ Year } \\
\hline & 1974 & 1975 & 1976 & 1977 & 1978 & 1979 & 1980 & 1981 & 1982 & 1983 & 1984 & 1985 & 1986 & 1987 & 1988 \\
\hline 2 & 26,059 & 36,087 & 46,560 & 58,319 & 34,447 & 9,127 & 23,609 & 94,540 & 54,746 & 34,853 & 51,203 & 21,036 & 15,112 & $42,686^{a}$ & $42,686^{a}$ \\
\hline 3 & 41,193 & 21,101 & 29,336 & 37,959 & 47.972 & 28,126 & 7,202 & 19,014 & 76,751 & 44,633 & 28,459 & 42,002 & 16,988 & 12,323 & 34,844 \\
\hline 4 & 14,809 & 27,128 & 15,981 & 22,045 & 29,499 & 37,883 & 19,346 & 5,262 & 13,087 & 58,492 & 34,078 & 22,222 & 32,221 & 12,744 & 8,789 \\
\hline 5 & 11,782 & 9,028 & 17,445 & 10,308 & 14,648 & 20,893 & 24,281 & 12,422 & 3,132 & 8,694 & 37,843 & 23,226 & 15,601 & 20.904 & 7,577 \\
\hline 6 & 4,544 & 6,921 & 5,088 & 9,515 & 6,244 & 8,684 & 13,079 & 13,772 & 6,676 & 1,803 & 5,443 & 22,186 & 13,807 & 8,776 & 10,255 \\
\hline 7 & 1,567 & 2,501 & 3,515 & 2,860 & 5,117 & 3,419 & 5.148 & 7,034 & 7,045 & 3,139 & 1.093 & 3,332 & 10,926 & 6.618 & 3,533 \\
\hline 8 & 619 & 920 & 1,116 & 1.676 & 1,402 & 2,325 & 2,112 & 2,775 & 3,288 & 3,412 & 1,789 & 709 & 1,478 & 4,912 & 2,704 \\
\hline 9 & 359 & 316 & 517 & 670 & 770 & 610 & 1.426 & 1.307 & 1,408 & 1,485 & 1.901 & 1,128 & 391 & 767 & 2,129 \\
\hline 10 & 307 & 208 & 187 & 387 & 363 & 265 & 356 & 867 & 793 & 648 & 727 & 1,260 & 710 & 196 & 385 \\
\hline 11 & 270 & 162 & 94 & 139 & 244 & 162 & 161 & 193 & 470 & 409 & 280 & 421 & 714 & 341 & 89 \\
\hline $12+$ & 150 & 142 & 255 & 848 & 542 & 466 & 279 & 452 & 574 & 806 & 635 & 553 & 674 & 616 & 434 \\
\hline \multicolumn{16}{|c|}{ Totals } \\
\hline Age $2+$ & 101,659 & 104,511 & 120,093 & 144,725 & 141,248 & 111,961 & 96,997 & 157,638 & 167,969 & 158,375 & 163,451 & 138,075 & 108,621 & 110,942 & 113,424 \\
\hline Spawners & 45,150 & 48,593 & 51,488 & 58.422 & 68.045 & 72,185 & 62,262 & 54,568 & 62,784 & 79,558 & 84,164 & 81,948 & 72.427 & 57,488 & 47,568 \\
\hline Age $6+$ & 7,816 & 11,168 & 10,772 & 16,094 & 14,682 & 15,932 & 22,560 & 26,400 & 20,254 & 11,703 & 11,869 & 29,589 & 28,700 & 22,225 & 19,529 \\
\hline
\end{tabular}

a 1974-84 average.

1). High levels of $F$ are associated with several dominant year-classes, particularly those produced from 1974 through 1976 and, more recently, 1979 through 1982. Total mortality estimates for these year-classes derived from bottom trawl survey data were also among the highest observed in the series (Table 8).

\section{Stock size estimates}

Final VPA results indicate a steady increase in total stock abundance (age 2+) from 102 million fish in 1974 to 145 million in 1977 , followed by a decline to 97 million in 1980 (Table 11). With the recruitment of the strong 1979 year-class at age 2, total stock abundance increased to 168 million fish in 1982 before declining to less than 1.15 million after 1986. Estimates of exploitable stock size (ages $6+$ ) exhibit a rather steady increase from 8 million fish in 1974 to 26 million in 1981, followed by a sharp decline to 12 million in 1983 and 1984 . Exploitable stock abundance increased temporarily to over 28 million fish in 1985 and 1986 due to contributions from the 1979 year-class, but had since declined. Estimates of stock biomass are less variable than abundance estimates. Total biomass (Table 12, Fig. 8) exhibited an overall increasing trend throughout 1984, but has subsequently declined. Exploitable biomass followed the same general trend with peak levels occurring in 1979 and 1984.

Spawning stock abundance (Table 11) increased steadily from 1974 to 1979 and remained relatively high between 1983 and 1985 as fish from the 1979 and 1982 year-classes attained sexual maturity. Spawning stock abundance has been steadily declining since 1984 , however, and the estimate for 1988 is the lowest since 1975. 
TABLE 12. Estimates of 1974-87 stock biomass (tons) derived from virtual population analysis (VPA) of Div. 4 VWX and Subareas 5 and 6 pollock catch-at-age, and projections for 1988

\begin{tabular}{|c|c|c|c|c|c|c|c|c|c|c|c|c|c|c|c|}
\hline \multirow[b]{2}{*}{ Age } & \multicolumn{15}{|c|}{ Year } \\
\hline & 1974 & 1975 & 1976 & 1977 & 1978 & 1979 & 1980 & 1981 & 1982 & 1983 & 1984 & 1985 & 1986 & 1987 & 1988 \\
\hline 2 & 21,369 & 31.035 & 27.936 & 48,405 & 28.936 & 6.663 & 22.428 & 58,615 & 32,847 & 25,443 & 52.739 & 14,725 & 12,089 & 30,734 & 30,734 \\
\hline 3 & 57.670 & 27,009 & 36.083 & 42.893 & 59,006 & 33.470 & 10.011 & 27.950 & 86.729 & 51,774 & 41.834 & 43.683 & 20,216 & 13,925 & 39,373 \\
\hline 4 & 29,025 & 53,984 & 30,523 & 35,271 & 53.098 & 62,128 & 37,724 & 13,049 & 33,372 & 97,097 & 73.267 & 42.888 & 59.608 & 24.724 & 17,050 \\
\hline 5 & 35,463 & 27,715 & 48,322 & 26,905 & 39,255 & 56,828 & 67,500 & 36,646 & 10,961 & 26,691 & 99,528 & 64.104 & 40,251 & 53,876 & 19,472 \\
\hline 6 & 18,583 & 26,644 & 18,774 & 33,586 & 24,664 & 30,656 & 45,906 & 47,239 & 27.704 & 7.502 & 19,104 & 71,662 & 46,942 & 26,679 & 31,176 \\
\hline 7 & 7.931 & 12,728 & 16,205 & 13.043 & 23.639 & 15.898 & 21.672 & 30,808 & 31,774 & 15,319 & 5.617 & 12.460 & 41,956 & 25,676 & 13,706 \\
\hline 8 & 3,787 & 6.001 & 6.195 & 9,505 & 8.119 & 13.136 & 11.930 & 16,178 & 17,359 & 17,640 & 10.287 & 3,653 & 7,152 & 21.071 & 11,600 \\
\hline 9 & 2,389 & 2,371 & 3,622 & 4,559 & 5,077 & 4,117 & 9,241 & 8,809 & 8,828 & 8,925 & 11.389 & 7,176 & 2,450 & 3,988 & $\$ 1,070$ \\
\hline 10 & 2,261 & 1,587 & 1,440 & 2,730 & 2,460 & 1,978 & 2,745 & 6,454 & 5,823 & 4,355 & 4,739 & 7,974 & 4,847 & 1,403 & 2,757 \\
\hline 11 & 2.304 & 1.371 & 802 & 1,224 & 1.848 & 1,329 & 1.267 & 1.482 & 3.659 & 3,155 & 2,108 & 2.794 & 4,787 & 2,514 & 655 \\
\hline $12+$ & 1.495 & 1.415 & 2.351 & 7,681 & 4.297 & 3,876 & 2.467 & 3.721 & 4.748 & 7.143 & 5.427 & 4,759 & 5.420 & 5.190 & 3,655 \\
\hline & \multicolumn{15}{|c|}{ Totals } \\
\hline Age 2+ & 182,277 & 191,859 & 192,252 & 225,803 & 250,398 & 230,077 & 232,893 & 250,950 & 263,804 & 265,045 & 326,039 & 275,878 & 245,718 & 209.778 & 181,248 \\
\hline Spawners & 112,585 & 126,696 & 128,895 & 139,275 & 165,316 & 178,060 & 186,961 & 169,437 & 164,916 & 177,392 & 219.325 & 213,176 & 198,753 & 159,083 & 119,252 \\
\hline Exploitable & 127,794 & 114,673 & 121.926 & 119.896 & 123.238 & 202.407 & 194.585 & 172,302 & 147.627 & 172,524 & 212.686 & 189.495 & 192,753 & 154.748 & -...-. \\
\hline Age $6+$ & 38,750 & 52,116 & 49,389 & 72,328 & 70.103 & 70,988 & 95,229 & 114,690 & 99,895 & 64,040 & 58.670 & 110.478 & 113.554 & 86.519 & 74,619 \\
\hline
\end{tabular}

Large fluctuations in total stock size since the mid1970 s result primarily from recruitment of the strong 1974, 1975, 1979, 1980 and 1982 year-classes. These year-classes have supported the fishery since the late1970s, while similarly strong 1969 and 1971 yearclasses predominated during the mid-1970s. Although strong year-classes have been produced approximately every $3-4$ years, the $1979-82$ period was especially productive. Recruitment of subsequent year-classes, however, has been extremely poor despite continued high spawning stock levels through 1986. Average recruitment at age 2 for the 1974-84 period (1972-82 year-classes) is estimated at 43 million fish. The 1979 year-class, totalling 95 million fish at age 2 , is the strongest to appear in the entire series, followed by the 1975 year-class at 58 million fish. Average recruitment for the more recent $1985-86$ period (18 million fish) is less than one-half of the long-term average.

\section{Equilibrium Yield and Stock Biomass}

\section{Yield-per-recruit}

Yield-per-recruit calculations were performed using the method of Thompson and Bell (1934). Commercial mean weights-at-age for ages 2-11 (Table 2), averaged over the 1974-87 period, were supplemented by mean weights for ages 12-16 derived from the von Bertalanffy growth function presented above. Natural mortality was fixed at 0.20 and partial recruitment followed the pattern described by the SVPA. Results indicate that maximum yield-per-recruit occurs at a fishing mortality rate $\left(F_{\max }\right)$ of 0.57 with $F_{0.1}$ equal to 0.29 (Fig. 9).

\section{Stock biomass and yield projections}

Stock biomass and resulting catches were projected under equilibrium conditions with recruitment at age 2 equal to the 1974-84 average of 43 million fish as

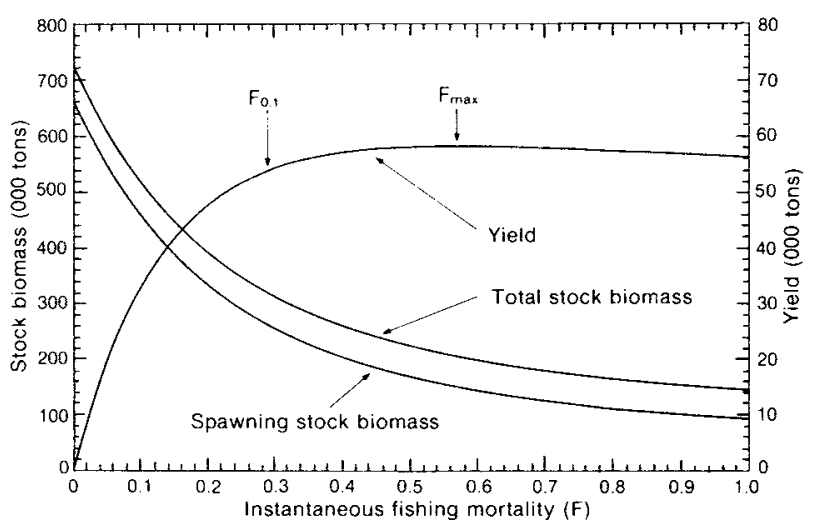

Fig. 9. Equilibrium yield, total stock and spawning stock biomass (000 tons) estimates for pollock in Div. 4VWX and Subarea 5 and 6 .

estimated from the final VPA. Year-classes subsequent to 1982 were excluded because of the inherent uncertainty in the most recent years introduced by the choice terminal F. Projections were run at fishing mortality rates ranging from 0.05 to 1.00 in increments of 0.05 and at the $F_{\max }$ and $F_{0.1}$ levels. Spawning stock biomass projections were also performed using an age-specific maturity schedule from our analyses for combined sexes.

Results suggest that fishing at $F_{0.1}(0.29)$ would provide a long-term yield of 53,600 tons from a stock biomass of 317,700 tons; fishing at $F_{\max }(0.57)$ would provide a long-term yield of 58,100 tons from a stock biomass of 204,600 tons (Fig. 9). Corresponding spawning stock biomass estimates at $F_{0.1}$ and $F_{\max }$ are 260,400 and 149,800 tons respectively. Although longterm yields are approximately $8 \%$ greater at the $F_{\max }$ level, fishing at $F_{0.1}$ provides for a $55 \%$ increase in total stock and a $74 \%$ increase in spawning stock biomass over those allowed under $F_{\max }$, thereby providing for greater stability in reproductive potential and resilience to environmental perturbations. Stock sizes in 1987 and 
1988 were intermediate to those predicted under $F_{0.1}$ and $F_{\max }$.

\section{Summary}

Pollock in the Northwest Atlantic have been subjected to increased fishing intensity since the mid1970 s, a trend which has accelerated since the USA and Canada implemented extended jurisdiction. Severe reductions in abundance of traditional groundfish resources, accompanied by increases in directed effort have led to a shift in the status of this resource from underexploited to fully exploited. Annual catch estimates for the USA recreational fishery have also increased during the early-1980s. This fishery is particularly sensitive to recruitment trends as indicated by changes in mean weight-at-age.

Assessment and management advice for pollock has traditionally been predicated on the assumption of a unit stock in Div. 4VWX and Subarea 5. However, analyses of migration patterns of fish tagged at inshore locations along the coast of Nova Scotia, in conjunction with morphometric and biochemical analyses, suggest a possible segregation of Gulf of Maine pollock from those on the Scotian Shelf. Additional tagging studies are needed in the Gulf of Maine to further clarify movement patterns and stock relationships throughout the region.

Overall pollock abundance appears to have increased considerably from the mid-1970s through the early-1980s. Although this increase in stock size was reflected in both USA and Canadian commercial CPUE indices, recent USA indices indicate a decline in stock biomass since 1984. Canadian CPUE indices, however, have remained relatively high since the early1980s. Each CPUE series may reflect local changes in pollock availability on different fishing grounds in recent years, implying a possible shift in the distribution of the stock. Seasonal fluctuations in availability may also influence CPUE results, but this effect was mitigated by basing the calculations on periods when pollock are dispersed throughout the region.

Both USA and Canadian research vessel survey indices exhibit considerable inter-annual variability, largely due to variations in year-class strength. Computation of NEFC stratified mean catch-per-tow estimates on a logarithmic scale with subsequent retransformation to original units reduced the variation, while general trends remained similar to those based on linear data (Mayo et al., 1989). Distinct differences in overall trends are also evident between USA and Canadian surveys, but such disparities are likely since USA coverage is limited primarily to Subareas 5 and 6 , while Canadian summer surveys are conducted almost exclusively in Div. 4VWX.
Relative strengths of dominant year-classes derived from bottom trawl surveys are consistent with commercial catch-at-age data and recruitment estimates obtained from virtual population analysis. Several strong year-classes, notably those of 1969, 1971 . 1975, 1979 and 1982 have appeared consistently throughout the 1970-87 period in Canadian and USA survey and commercial data sets. In addition, the strong 1979 and 1982 year-classes were detected at ages 0 and 1 by the coastal survey conducted by the Commonwealth of Massachusetts in the western Gulf of Maine. The strongest year-classes have been tracked with reasonable consistency in all offshore surveys. Recruitment to offshore surveys has generally not been complete before age 3 or 4 , however, which seriously impairs their predictive value. Massachusetts inshore surveys, however, are useful for predictive purposes at ages 0 and 1 , indicating the need for more intensive coverage of inshore areas if management programs require accurate predictions of year-class strength.

Growth patterns were consistent between the Gulf of Maine and Scotian Shelf. Since the USA samples were collected from the Gulf of Maine and Canadian samples were collected primarily on the Scotian Shelf, it appears that growth patterns are similar in both areas and that the interpretation of annular rings on otoliths is consistent between the two countries. Differential growth by sex was also shown to be negligible.

Estimated lengths at 50\% maturity based on USA and Canadian observations pooled over several years were virtually identical for female pollock; the $L_{50}$ calculated for males was $2-3 \mathrm{~cm}$ higher than estimates obtained for females. Computed median ages-atmaturity derived from these lengths were also slightly greater for males.

Above average mortality rates were associated with several dominant year-classes which have supported the fishery since the mid-1970s. Over the last decade, the recruitment of these strong year-classes has attracted additional fishing effort and may have increased relative exploitation on younger ages. Estimates of average fishing mortality derived from the VPA increased in 1981 and 1982 due, in part, to elevated levels of $F$ on the 1974-76 year-classes. Decreased fishing mortality in 1983 and 1984 corresponded to a temporary decline in landings and fishing effort, while subsequent increases in effort between 1985 and 1987 resulted in unusually high Fs on the 1979-81 yearclasses.

Termainal $F$ values used to start the VPA calculations were derived by the Hybrid method, one of several integrated tuning procedures described by Pope and Shepherd (1985), which incorporates catch-at-age and 
effort information from individual fleets components. The resulting $F$ matrix thus reflects the combined effort trends and catchability of each fleet weighted by the inverse of its variance. In these analyses, $q$ was held constant for the USA fleet and allowed to fluctuate for the Canadian fleet. This approach was considered appropriate, given the recent inter-annual fluctuations in Canadian CPUE and the possible variation in q over time associated with changing stock sizes. Thus, the relatively high terminal $F$ estimates for 1987 reflect the sharp decline in USA and, to a lesser extent, Canadian CPUE associated with increased fishing effort.

Results from the VPA suggest that stock size increased during the late-1970s and early 1980s, but has declined since 1982. Spawning stock also increased during the past decade due to contributions from the strong 1975, 1979 and 1982 year-classes, and the recent increase in pollock landings is also related to recruitment of these year-classes. The most recent decline in spawning stock coincided with high mortality rates on the 1979-82 year-classes in 1986 and 1987. Stock biomass estimates exhibit less variability over time, although they follow the same trends as stock abundance.

A recent decline in pollock abudance is consistent with yield-per-recruit considerations since fishing mortality has been close to $F_{\max }$ in 4 of the 6 years since 1982. It has been demonstrated that continued fishing at $F_{\max }$ or maintaining yields at MSY levels will result in long-term declines in spawning stock, since these strategies do not account for random fluctuations in recruitment and environmental conditions (Doubleday, 1976; Sissenwine, 1977). This problem is compounded when the relationship between yield-per-recruit and $F$ is flat-topped as in the case of pollock (Fig. 9). A more conservative strategy, although somewhat arbitrary, is to reduce fishing mortality to the $F_{0.1}$ level which will provide, on a long-term basis, approximately $90 \%$ of the $F_{\max }$ yield at one-half the fishing-mortality rate. At this lower level of $F$, total and spawning stock biomass levels are 55 and $74 \%$ higher than for corresponding $F_{\max }$ levels. These reference fishing-mortality rates are higher than previous estimates reported by Mayo and Clark (MS 1984) which were computed on the basis of full fishing mortality on all ages greater than 5 years. Our estimate of $F_{0.1}(0.29)$, however, is similar to the 0.28 calculated by McGlade et al. (1986) based on simulations incorporating variable recruitment.

Although the incorporation of a dome-shaped partial recruitment vector in the equilibrium yield projections has resulted in higher reference $F$ levels and lower biomass estimates than those obtained from previous analyses, this exploitation pattern is consistent with technological interactions exhibited by the various gear components employed within the overall fishery.
One can conclude, therefore, that fishing mortality rates in the range of $0.30-0.40$ are conducive to longterm stability of this stock under average recruitment conditions. Although we do not understand the mechanisms controlling year-class strength, we note that one or more strong year-classes have appeared throughout the Scotian Shelf - Gulf of Maine region every 3 to 4 years since the late-1960s. A possible densitydependent recruitment link is suggested since the median age at maturity for pollock is approximately 3.5 years. Production of several strong year-classes between 1979 and 1982 occurred after a prolonged period of increasing spawning biomass although recent production has been relatively poor. Maintenance of the spawning stock at levels observed during the preceding decade, however, should enhance reproductive stability and provide for sustained yields to the fishery of about 55,000 tons.

\section{Acknowledgements}

The authors thank D. Beanlands, M. C. Annand, J. Oppenheimer, C. MacMurray and B. Figuerido for their assistance in data analysis, drafting and preparation of tables. R. G. Halliday, W. J. Overholtz and G. Shepherd offered many constructive comments on the original draft and F. M. Serchuk provided valuable advice on VPA tuning and SVPA approaches. The criticism provided by two anonymous referees is sincerely appreciated.

\section{References}

ACKERMAN, E. A. 1941. New England's Fishing Industry. The University of Chicago Press, Chicago, Illinois, $303 \mathrm{p}$.

ALMEIDA, F. P., M. J. FOGARTY, S. H. CLARK, and J. S. IDOINE, MS 1986. An evaluation of precision of abundance estimates derived from bottom trawl surveys off the northeastern United States. ICES C.M. DOC., No. G:91, $19 \mathrm{p}$.

ANNAND, M. C., D. BEANLANDS, J. MCMILLAN, and R. O'BOYLE, MS 1987. The status of the NAFO Divisions $4 \mathrm{VWX}+$ Subarea 5 pollock resource during 1970-1986 with yield projected to 1988. CAFSAC Res. Doc., No. 96, $56 \mathrm{p}$.

ANNAND, M. C., D. BEANLANDS, and J. MCMILLAN. MS 1988. Assessment of Divisions $4 \mathrm{VWX}$ and SA 5 pollock (Pollachius virens). CAFSAC Res. Doc., No. 71, 65 p.

AZAROVITZ, T. R. 1981. A brief historical review of the Woods Hole Laboratory trawl survey time series. In: Bottom trawl surveys, W. G. Doubleday and D. Rivard (ed.). Can. Spec. Publ. Fish. Aquat. Sci., 58: 62-67.

BEACHAM, T. D. 1983. Variability in size or age at sexual maturity of white hake, pollock, longfin hake, and silver hake in the Canadian Maritimes area of the Northwest Atlantic ocean. Can. Tech. Rep. Fish. Aquat. Sci., 1157: iv $+43 p$.

BIGELOW, H. B., and W. C. SCHROEDER. 1953. Fishes of the Gulf of Maine. Fish. Bull., U.S., 53: 577 p.

BLISS, C.I. 1967. Statistics in Biology; Statistical Methods for 
Research in the Natura! Sciences, Vol. I. McGraw-Hill, New York, $558 \mathrm{p}$.

BOLZ, G. R., R. G. LOUGH, and D. C. POTTER. 1981. Autumn and winter abundance and distribution of ichthyoplankton on Georges Bank and Nantucket Shoais, 1974-1976, with special emphasis on dominant species. ICES Rapp. Proc.-Verb., 178: 168-170.

CLARK, S. H., T. S. BURNS, and R. G. HALLIDAY, MS 1976. A preliminary assessment of the pollock fishery in ICNAF Divisions 4VWX and Subarea 5. ICNAF Res. Doc., No. 47, Serial No. 3833, $27 p$

1977. Assessment of the pollock fishery in ICNAF Divisions 4VWX and Subarea 5. ICNAF Sel. Pap., 2: 15-32.

CLARK, S. H., L. CLEARY, and T. S. BURNS. MS 1978. A review of the Northwest Atlantic pollock resource. ICES C.M. Doc., No. G:61, 33 p.

CLARK, S. H., W. J. OVERHOLTZ, and R. C. HENNEMUTH 1982. Review and assessment of the Georges Bank and Gulf of Maine haddock fishery. J. Northw. Atl. Fish. Sci. 3 $1-27$.

COLTON, J. B., Jr., and R. R. BYRON. 1977. Gulf of MaineGeorges Bank ichthyoplankton collected on ICNAF larval herring surveys, September 1971-February 1975. NOAA Tech. Rep. NMFS (Spec. Sci. Rep. Fish.), 717: $35 \mathrm{p}$

COLTON, J. B., Jr., W. G. SMITH, A. W. KENDALL, Jr., P. L. BERRIEN, and M. P. FAHAY. 1979. Principal spawning areas and times of marine fishes, Cape Sable to Cape Hatteras. Fish. Bull., U.S., 76(4): 911-915.

DIXON, W. J. (ed.). 1981. BMDP Statistical Software. University of California Press, p. 330-344.

DOUBLEDAY, W. G. 1976. Environmental fluctuations and fisheries management. ICNAF Sel. Pap., 1: 141-150.

FAWCETT, R. F., MS 1983. New Hampshire coastal anadromous fish restoration and marine recreational fishery evaluation 1: A creel survey of the summer marine recreational fishery. Completion Report: D-J Project No. F-36-R-10, 26 p.

FREEMAN, B. L., and L. A. WALFORD. 1979a. Anglers guide to the United States Atlantic coast, Section I: Passamaquoddy Bay, Maine to Cape Cod, NOAA, Nat. Mar. Fish. Serv., Seattle, WA 13 p.

1979b. Anglers guide to the United States Atlantic coast, Section III: Block Island to Cape May, New Jersey, NOAA, Nat. Mar. Fish. Serv., Seattle, WA, 20 p.

GRICE. F. MS 1971. Disaster relief: Massachusetts haddock fishery. Completion Report: PL88-309, Project No. 3-107-R-1, $8 \mathrm{p}$.

GROSSLEIN, M. D. 1969. Groundfish survey program of BCF Woods Hole. Comm. Fish. Rev., 31(8-9): 22-35.

MS 1974. Bottom trawl survey methods of the Northeast Fisheries Center, Woods Hole, Massachusetts, USA. ICNAF Res. Doc., No. 96, Serial No. 3332.

GULLAND, J. A. 1964. Catch per unit of effort as a measure of abundance. ICES Rapp. Proc.-Verb., 155(1): 8-13.

1965. Estimation of mortality rates. Annex to Rep. Arctic Fish. Working Group, Int. Cons. Explor. Mer. C.M. 1965(3): $9 \mathrm{p}$

GULLAND, J . A., and D. HARDING. 1961. The selection of Clarias mossambicus (Peters) by nylon gill nets. ICES J. Cons., 26: 215-222.

GULLAND, J. A., and L. K. BOEREMA. 1973. Scientific advice on catch levels. Fish. Bull., U.S., 71(2): 325-335.

HALLIDAY, R. G. MS 1976. A preliminary assessment of the pollock fishery in ICNAF Divisions $4 \mathrm{VWX}$ and Subarea 5.
ICNAF Res. Doc., No. 47, Serial No. 3833, 3 p.

HALLIDAY, R. G., and P. A. KOELLER. 1981. A history of Canadian groundfish trawling surveys and data usage in ICNAF Divisions 4TVWX. In: Bottom traw! surveys, W. G. Doubleday, and D. Rivard (ed.). Can. Spec. Publ. Fish. Aquat. Sci, 58: 27-41.

HOBERMAN, J. M., and A. C. JENSEN. 1962. The growth rate of New England pollock. Trans. Amer. Fish. Soc., 91: 227228.

HOWE, A. B., D. MacISAAC, B. T. ESTRELLA, and F. J. GERMANO, Jr. MS 1979. Fishery resource assessment, coastal Massachusetts. Completion Report, Massachusetts Div. Mar. Fish., Commercial Fish. Res. Dev. Project No. 3-287-R-1, $34 \mathrm{p}$.

ICNAF, 1973. Proceedings of the Special Commission Meeting, January 1973 and the 23rd Annual Meeting, June 1973. ICNAF Meet. Proc., 1973, 214 p.

1976. Report of standing committee on research and statistics. Part C. ICNAF Redbook, 1976: 51-165.

1960-78. Fishery statistics for the years 1960-78. ICNAF Stat. Bull., vols. 10-28.

IHSSEN, P. E., H. E. BOOKE, H. M. CASSELMAN, J. M. MCGLADE, N. R. PAYNE, and F. M. UTTER. 1981. Stock identification: materials and methods. Can.J. Fish. Aquat. Sci. 38: 1838-1855.

JENSEN, A. C. MS 1967. A brief history of the New England offshore fisheries. U.S. Fish and WildI. Serv., Fish. Leaflet, No. 594,14 p.

LEIM, A. H., and W. B. SCOTT. 1966. Fishes of the Atlantic Coast of Canada. Bull. Fish. Res. Board Can., 155: $212-214$

MARAK, R. R., and J. B. COLTON, Jr. 1961. Distribution of fish eggs and larvae, temperature, and salinity in the Georges Bank - Gulf of Maine area, 1953. U.S. Fish Wildl. Serv., Spec. Sci. Rep.-Fish., 398: 61 p.

MAVOR, J. W. 1918. On the age and growth of the pollock in the Bay of Fundy. Contrib. Can. Biol. 1917-1918, p. 111-125.

MAYO, R. K., and S. H. CLARK. MS 1984. An assessment of the pollock (Pollachius virens L.) stock in the Scotian Shelf, Gulf of Maine, and Georges Bank region, 1984. U.S. Nat. Mar. Fish. Serv., Northeast Fisheries Center, Woods Hole Lab. Ref. Doc. No. 84-13, 42 p

MAYO, R. K., S. H. CLARK, and M. C. ANNAND. 1989. Stock assessment information for pollock, Pollochius virens (L.) in the Scotian Shelf, Georges Bank, and Gulf of Maine, region. NOAA Tech. Memo., NMFS-F/NEC-65: $30 \mathrm{p}$.

MCGLADE, J. M. MS 1983. Preliminary study of the stock structure of pollock (Pollachius virens L.) on the Scotian Shelf and in the Gulf of Maine. CAFSAC Res. Doc., No. 81, $21 \mathrm{p}$.

MCGLADE, J. M., M. C. ANNAND, and T. J. KENCHINGTON. 1983. Electrophoretic identification of Sebastes and Helicolenus in the northwestern Atlantic. Can. J. Fish. Aquat. Sci., 40: 1861-1870.

MCGLADE, J. M., M. C. ANNAND, and D. BEANLANDS. MS 1985. The exploitation and biological status of pollock in Divisions $4 \mathrm{VWX}$ and Subarea 5. CAFSAC Res. Doc., No. 99, $90 \mathrm{p}$.

McGLADE, J. M., M. C. ANNAND, D. BEANLANDS, and A. SINCLAIR. MS 1986. Assessment of Divisions 4VWX and SA 5 pollock, Pollachius virens. CAFSAC Res. Doc., No. $118,45 \mathrm{p}$.

MCGLADE, J. M., and M. C. ANNAND. MS 1986. Revision of 
the catch-at-age matrix for pollock (Pollachius virens) in Divisions $4 \mathrm{VWX}$ and Subarea 5. CAFSAC Res. Doc., No. $119,42 \mathrm{p}$.

MCGLADE, J. M., and E. BOULDING. 1986. The truss: A geometric and statistical approach to the analysis of form in fishes. Can. Tech. Rept. Fish. Aquat. Sci., 1457: 68 p.

MORSE, W. W., M. P. FAHAY, and W. G. SMITH. 1987. MARMAP Surveys of the Continental Shelf from Cape Hatteras, North Carolina to Cape Sable, Nova Scotia (19771984). Atlas No. 2, Annual Distributional Patterns of Fish Larvae. NOAA Tech. Mem. NMFS-F/NEC-47: 215 p.

NAFO. 1979-85. Fishery statistics for the years 1979-85. NAFO Stat. Bull., vols. 29-35.

1987. Provisional nominal catches in the Northwest Atlantic, 1986. NAFO SCS Doc., No. 20, Serial No. N1362, $53 \mathrm{p}$.

1988. Provisional nominal catches in the Northwest Atlantic, 1987. NAFO SCS Doc., No. 18, Serial No. N1521, $59 \mathrm{p}$.

NERFMC. MS 1978. Draft final fishery management pian for the pollock fishery of the northwestern Atlantic. New England Regional Fishery Management Council, Peabody, M. A., 139 p.

NICHOLSON, L. E., and R. P. RUAIS. MS 1979. Description of the recreational fisheries for cod, haddock, pollock, and silver hake off the northeast coast of the United States. New England Regional Fishery Management Council, Peabody, MA, $118 \mathrm{p}$

O'BOYLE, R. N., M. SINCLAIR, R. J. CONOVER, K. H. MANN, and A. C. KOHLER. 1984. Temporal and spatial distribution of ichthyoplankton communities of the Scotian Shelf and relation of biological, hydrological, and physiographic features. ICES Rapp.-Proc.-Verb., 183: 27-40.

POPE, J. G., and D. J. GARROD. 1975. Sources of error in catch and effort quota regulations with particular reference to variations in the catchability coefficient. ICNAF Res. Bull., 11: 17-30.

POPE, J. G., and J. G. SHEPHERD. 1982. A simple method for the consistent interpretation of catch-at-age data. ICES J.

Cons., 40: 176-184.

1985. A comparison of the performance of various methods for tuning VPAs using effort data. ICES J. Cons., 42: 129-151.

SCOTT, J. S. 1980. Occurrence of pollock, Pollachius virens, and sand lance, Ammodytes sp., larvae in the Bay of Fundy. J. Northw. Atlant. Fish. Sci., 1: 45-48.

1982. Depth, temperature, and salinity preferences of common fishes of the Scotian Shelf. J. Northw. Atlant. Fish. Sci., 3: 29-39.

SETTE, O. E., and R. H. FIEDLER. MS 1929. Fishing industries of the United States, 1927. Bur. Fish., Doc. No. 1050, p. 401-547.

SHEPHERD, J. G. 1983. Two measures of overall fishing mortality. ICES J. Cons., 41: 76-80.

SHERMAN, K. 1980. MARMAP, a fisheries ecosystem study in the NW Atlantic: Fluctuations in ichthyoplanktonzooplankton components and their potential for impact on the system. In: Diemer, F. P., Vernberg, F. J., Mirkes, D. Z. (ed.). Advance Concepts in Ocean Measurements for Marine Biology. Belle W. Baruch Institute for Marine Biology and Coastal Research, Univ. of South Carolina Press, Berkeley, p. 9-37.

SHERMAN, K., R. MAURER, R. BYRON, and J. GREEN. 1981. Relationship between larval fish communities and zooplankton prey species in an offshore spawning ground ICES Rapp. Proc.-Verb., 178: 289-294.

SISSENWINE, M. P. 1977. The effect of random fluctuations on a hypothetical fishery. ICNAF Sel. Pap., 2: 137-144.

STEELE, D. H. 1963. Pollock, (Pollachius virens (L.)) in the Bay of Fundy. J. Fish. Res. Board Can., 20(5): 1267-1314.

STOROZHUK, A. Y. 1978. Age-related features of the metabolism of the coalfish, Pollachius virens. J. Ichthyol., 18(4): 655-665.

STRAUSS, R. E., and F. L. BOOKSTEIN. 1982. The truss: body form reconstruction in morphometrics. Syst. Zool., 31(2): 113-135

TEMPLEMAN, W. 1966. Marine resources of Newfoundland. Bull. Fish. Res. Board Can., 154: 170 p.

THOMPSON, W. F., and F. H. BELL. 1934. Biological statistics of the Pacific halibut fishery. 2. Effects of changes in intensity upon total yield and yield per unit of gear. Rep. Int. Pacif. Halib. Comm., 8: 49 p.

TOMLINSON, P. K., and N. J. ABRAMSON. 1961. Fitting the von Bertalanffy growth curve by least squares. Fish. Bull. Calif. Dept. Fish Game, 116: 69 p.

US Dept. Commerce. 1984. Marine recreational fishery statistics survey, Atlantic and Gulf coasts, 1979 (Revised)-1980. NOAA, Nat. Mar. Fish. Serv., Curr. Fish. Stat., No. 8322, $239 \mathrm{p}$.

1985a. Marine recreational fishery statisitcs survey, Atlantic and Gulf coasts, 1981-1982. NOAA, Nat. Mar. Fish. Ser., Curr. Fish. Stat., No. 8324, 215 p.

1985b. Marine recreational fishery statistics survey, Atlantic and Gulf coasts, 1983-1984. NOAA, Nat. Mar. Fish. Serv., Curr. Fish. Stat., No. 8326, $222 \mathrm{p}$.

1986. Marine recreational fishery statistics survey, Atlantic and Gulf coasts, 1985. NOAA, Nat. Mar. Fish. Serv., Curr. Fish. Stat., No. 8327, $130 \mathrm{p}$.

1987. Marine recreational fishery statistics survey, Atlantic and Gulf coasts, 1986. NOAA, Nat. Mar. Fish. Serv., Curr. Fish. Stat., No. 8392, 127 p.

WILK, S. J., W. J. CLIFFORD, and D. J. CHRISTENSEN, MS 1979. The recreational fishery for pollock (Pollachius virens) in southern New England and the Middle Atlantic. U.S. Nat. Mar. Fish. Serv., Northwest Fisheries Center, Sandy Hook Laboratory Ref. Doc. No. 79-31, 5 p. 